\title{
The coenzyme A biosynthetic pathway: a new tool for prodrug bioactivation
}

Dustin Duncan and Karine Auclair*

Department of Chemistry, McGill University, Sherbrooke Street West, Montreal, Quebec, Canada, H3A OB8

*Corresponding author: karine.auclair@mcgill.ca

\begin{abstract}
Prodrugs account for more than 5\% of pharmaceuticals approved worldwide. Over the past decades several prodrug design strategies have been firmly established; however, only a few functional groups remain amenable to this approach. The aim of this overview is to highlight the use of coenzyme A (CoA) biosynthetic enzymes as a recently explored bioactivation scheme and provide information about its scope of utility. This emerging tool is likely to have a strong impact on future medicinal and biological studies as it offers promiscuity, orthogonal selectivity, and the capability of assembling exceptionally large molecules.
\end{abstract}

Keywords: prodrug; bioactivation; coenzyme A; pantothenate; pantothenamide

\author{
Abbreviations \\ CoA - coenzyme A \\ AcCoA - acetyl coenzyme A \\ PanK - pantothenate kinase \\ PPCS - 4'-phosphopantothenoylcysteine synthetase \\ PPC-DC - 4'-phosphopantothenoylcysteine decarboxylase \\ PPAT - phosphopantetheine adenylyltransferase \\ DPCK - dephospho-CoA kinase \\ ATP - adenosine triphosphate \\ PanK $_{I}$ - pantothenate kinase Type I \\ PanK $_{\text {II }}$ - pantothenate kinase Type II \\ PanK $_{\text {III }}$ - pantothenate kinase Type III \\ ASKHA - acetate and sugar kinase/hsp70/actin \\ SAR - structure-activity relationship \\ $\mathrm{ACP}$ - acyl carrier protein \\ AAC(6') - aminoglycoside $N$-6'-acetyltransferase \\ Icl - isocitrate lyase \\ Ict - itaconyl-CoA transferase \\ Ich - itaconyl-CoA hydratase \\ $\mathrm{Ccl}-(S)$-citramalyl-CoA lyase
}


(C) This manuscript version is made available under the CC-BY-NC-ND 4.0 license

https://creativecommons.org/licenses/by-nc-nd/4.0/

\section{Preface and coenzyme A biosynthesis}

This review is dedicated to Prof. Paul Ortiz de Montellano, whose research has had a tremendous impact in numerous fields, one of which is the study of prodrug bioactivation by monooxygenases[1-3]. Prodrugs are chemically modified versions of an active molecule that must undergo transformation to release the functional product, typically implicating one or more enzyme catalysts. The prodrug approach is useful to fine-tune the properties of a lead compound, clinical candidate, or drug. As previously reviewed elsewhere[4-5], the design of a prodrug may aim to improve solubility or bioavailability, modify the absorption, distribution, metabolism or excretion, reduce off-target effects, and/or increase membrane penetration of a molecule. The concept has also found use in chemical biology studies.

This review focuses on bioactivation of molecules by enzymes involved in the biosynthesis of coenzyme A (CoA) from pantothenate (vitamin B5). CoA is an essential cofactor utilized in all domains of life, mainly as an organic acyl carrier (e.g. acetyl or succinyl groups in AcCoA and succinyl-CoA, respectively). Except for a small variation in Archaea (vide infra), the canonical biosynthesis of CoA from pantothenate is functionally well conserved across all domains of life, involving 5 enzymes (Fig. 1): pantothenate kinase (PanK), 4'-phosphopantothenoylcysteine synthetase (PPCS), 4'-phosphopantothenoylcysteine decarboxylase (PPC-DC), phosphopantetheine adenylyltransferase (PPAT), and dephospho-CoA kinase (DPCK), which are the gene products of $\operatorname{coaA}$ (or $\operatorname{coaX}$ ), $\operatorname{coa}$, $\operatorname{coa}$, $\operatorname{coaD}$, and $\operatorname{coa} E$, respectively. PanK catalyzes the phosphorylation of pantothenate at the primary alcohol, PPCS and PPC-DC append the cysteamine moiety through the formation of an amide, PPAT is responsible for adding the adenosyl group, and DPCK phosphorylates this new moiety at the 3'-OH. The current understanding of CoA biosynthesis was recently reviewed in more detail elsewhere[6].

In some organisms, a parallel route for CoA biosynthesis, known as the CoA salvage pathway, starts directly from pantetheine instead of pantothenate, and thus bypasses PPCS and PPC-DC (Fig. 1)[7]. Existence of this pathway implies that PanK must not only accept pantothenate as a substrate but also tolerate substituents at the carboxylate end, as with pantetheine. The high tolerance of PanK, PPAT and DPCK from several microorganisms for substrates derivatized at the thiol end is now well established and has been exploited in various contexts, ranging from the chemoenzymatic synthesis of alternative substrates to probe the mechanism of enzymes using CoA derivatives, to the in cellulo bioactivation of inhibitors which target enzymes acting on acyl-CoA substrates. Although the biosynthetic steps are well conserved, enzyme structural and mechanistic differences exist that allow organism-specific activation, making it a promising new tool for prodrug bioactivation.

Whereas there are only a few examples reported of inhibitors activated by CoA biosynthetic enzymes, the antimicrobial action of pantothenamides in some microorganisms has recently been discovered to also involve these enzymes to produce CoA antimetabolites which affect downstream CoA-utilising enzymes. This review aims to discuss molecules known to be transformed by CoA biosynthetic enzymes and to provide a scope of applicability for this bioactivation route. 


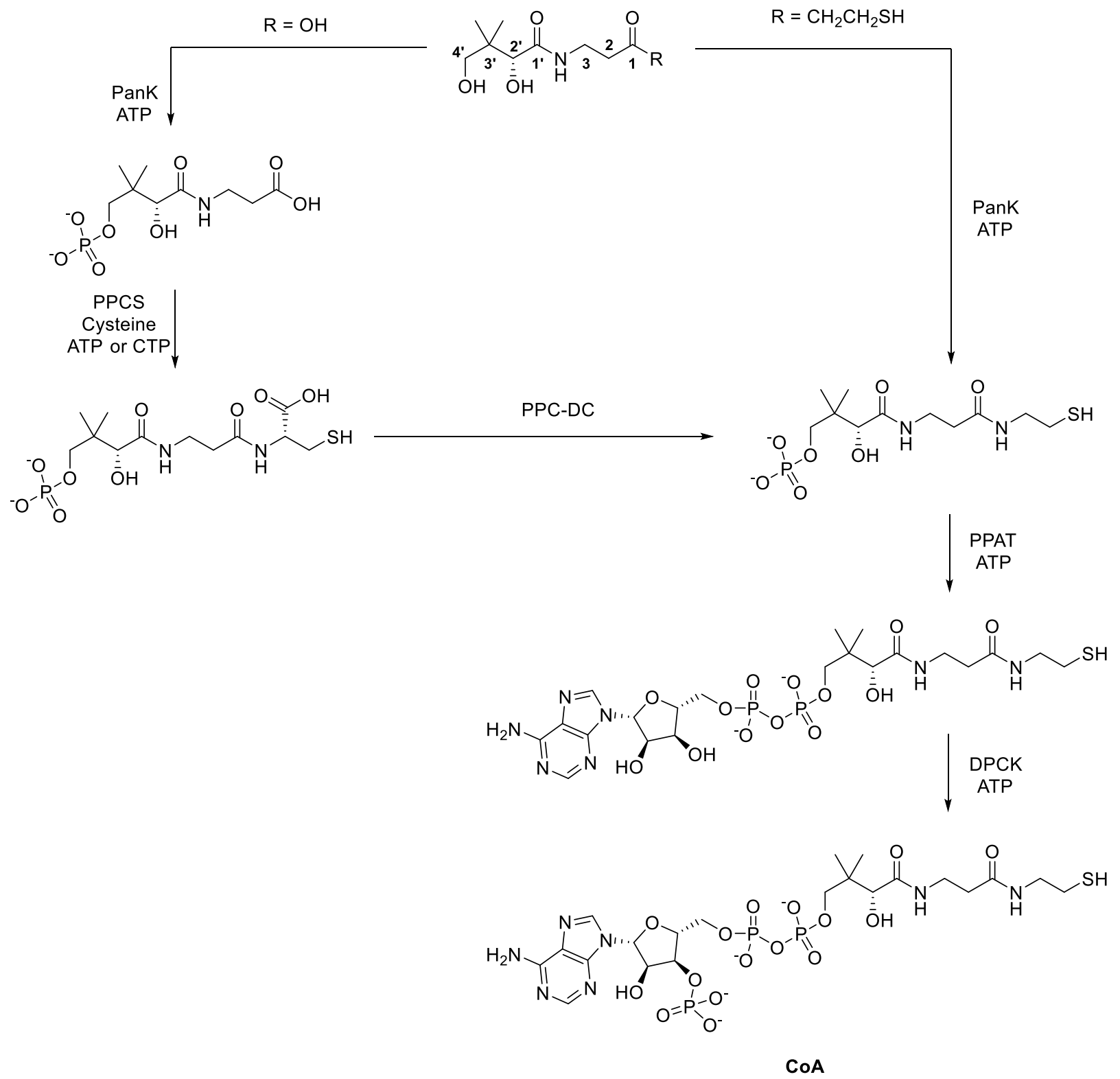

Figure 1: Biosynthesis of $\operatorname{CoA}$ from pantothenate or pantetheine.

\section{General differences between PanK , PanK $_{I I}$, and PanK $K_{I I}$}

In the design of molecules activated by the CoA biosynthetic pathway, understanding the nature and limits of substrate tolerance displayed by these enzymes is essential. The first step of CoA biosynthesis from pantothenate or pantetheine is phosphorylation by PanK. This activity is widely observed in the domains of Bacteria and Eukarya, but not Archaea (although a 4'phosphopantothenate synthetase has been described in Archaea, its substrates are 4'phosphopantoate and $\beta$-alanine rather than pantothenate and ATP)[8]. PanK types are typically classified into Type I, Type II, and Type III (PanK, PanK $_{I I}$, and PanK $\left.\mathrm{PII}\right)$ [9]. The differences 
between these three types of PanK (summarized in Table 1) allow for development of prodrugs that can be tuned to a particular system. Although bacteria are known to harbor PanK enzymes from any of the 3 Types, so far a PanK $\mathrm{II}_{\text {II }}$ has only been observed in Staphylococci $\mathrm{spp}$. Eukaryotes, on the other hand, express only PanK $_{\text {II }}[9]$. Notably, there is very low identity between the bacterial and human PanK $\mathrm{II}_{\mathrm{II}}[10]$, which may allow selective activation of molecules in bacteria for example. PanK $K_{I}$ and $P_{a n K}$ II accept a broad range of substrates, whereas PanK $K_{I I I}$ is very selective for pantothenate, hindering its exploitation.

Some bacteria harbor genes for two types of PanK, but whether both types are functional depends on the species. For example, although the genome of Mycobacterium tuberculosis encodes both a PanK $\mathrm{K}_{\mathrm{I}}$ and a $\mathrm{PanK}_{\mathrm{III}}$, only the $\mathrm{PanK}_{\mathrm{I}}$ is believed to be functional[11], whereas Bacillus anthracis $\mathrm{PanK}_{\mathrm{III}}$ is functional, while its $\mathrm{PanK}_{\text {II }}$ is not[12]. Interestingly, Bacillus subtilis produces two functional PanKs, a PanK I and a PanK $\mathrm{III}_{\text {II }}$ yet the PanK $\mathrm{K}_{\mathrm{I}}$ alone is sufficient to replenish the CoA pool[13]. A detailed list of the types of PanK encoded by various organisms as determined by phylogeny was reported by Yang et al[9].

Table 1: Key traits of PanK enzymes depending on their type

\begin{tabular}{|c|c|c|c|}
\hline & $\operatorname{PanK}_{\mathrm{I}}(\mathrm{CoaA})$ & $\operatorname{PanK}_{\text {II }}$ & $\operatorname{PanK}_{\text {III }}(\mathrm{CoaX})$ \\
\hline Domains found in & Bacteria & $\begin{array}{c}\text { Eukarya and } \\
\text { Bacteria (rare) }\end{array}$ & Bacteria \\
\hline CoA feedback inhibition & Yes & $\begin{array}{l}\text { Yes (Eukarya) } \\
\text { No (Bacteria) }\end{array}$ & Varies \\
\hline Broad substrate scope & Yes & Yes & No \\
\hline Fold superfamily & P-loop kinase & ASKHA & ASKHA \\
\hline Ions required $^{\mathrm{a}}$ & $\mathrm{Mg}^{2+}$ & $\mathrm{Mg}^{2+}$ & $\begin{array}{c}\mathrm{Mg}^{2+} \text { and } \mathrm{K}^{+} \text {or } \\
\mathrm{NH}_{4}{ }^{+}\end{array}$ \\
\hline Accepting pantothenamide substrates & Yes & Yes (Bacteria) & No \\
\hline
\end{tabular}

${ }^{\mathrm{a}}$ For PanK $\mathrm{K}_{\text {III }}$, some organisms can utilize other monovalent cations

\section{Structure and CoA feedback within PanKI, PanKII, and PanKIII}

In bacteria, the synthesis of CoA is regulated by feedback inhibition within PanK by CoA and CoA thioesters[14-16], for all PanK types except PanK $\mathrm{III}_{\text {II }}$ ]. In addition to recognition sites for both of its substrates ATP and pantothenate, Escherichia coli PanK $\mathrm{K}_{\mathrm{I}}\left(E c \mathrm{PanK} \mathrm{K}_{\mathrm{I}}\right)$ can also bind CoA to form an inhibited complex. Crystal structures of $E c \mathrm{PanK}_{\mathrm{I}}[17-18]$ show that although both ATP and CoA comprise an adenosyl moiety, the binding of each to the active site differ significantly, yet both interact with Lys101. Mutation of this residue (L101M) abrogates activity in $E c P a n K_{I}$ by greatly increasing the $\mathrm{K}_{\mathrm{M}}$ of ATP[19]. The thiol of CoA interacts with a bulky Phe252, which explains the slightly higher affinity of the enzyme for CoA than for CoAthioesters[17]. The intracellular concentration of CoA $(30-120 \mu \mathrm{M})$ is often high enough to favor binding of the molecule to free $\mathrm{PanK}_{\mathrm{I}}\left(\mathrm{K}_{\mathrm{d}}=6 \mu \mathrm{M}\right)$ [20]. The PanK $\mathrm{K}_{\mathrm{I}}$ enzymes of Mycobacterium tuberculosis[21-26], Klebsiella pneumoniae[27-28] and Coxiella burnetii PanK $\mathrm{K}_{\mathrm{I}}$ 29] have also 
(C) This manuscript version is made available under the CC-BY-NC-ND 4.0 license

https://creativecommons.org/licenses/by-nc-nd/4.0/

been crystallized. $M t \mathrm{PanK}_{\mathrm{I}}$ has high structural homology to $E c \mathrm{PanK}_{\mathrm{I}}$, except at the quaternary level wherein $M t \mathrm{PanK}_{\mathrm{I}}$ is a symmetric dimer while $E c \mathrm{PanK} \mathrm{K}_{\mathrm{I}}$ is an asymmetric $\operatorname{dimer}[21] . K p P a n \mathrm{~K}_{\mathrm{I}}$, also displays high sequence and structural homology to $E c P a n K_{I}$ (90\% sequence identity), with subtle differences in the binding pocket suggesting that the design of selective substrates may be conceivable[27].

Although typically associated with eukaryotic cells, a PanK II is also produced by Staphylococci spp.[30] Staphylococcus aureus $\mathrm{PanK}$ ( $\mathrm{SaPanK} \mathrm{KI}_{\text {II }}$ has been crystallized both in complex with a non-hydrolyzable ATP derivative and in complex with a phosphorylated pantothenamide and ADP (following addition of the pantothenamide and ATP)[28,31-32]. Whereas PanK $\mathrm{III}_{\text {II }}$ and PanK $\mathrm{III}_{\text {II }}$ belong to the same superfamily of fold, their 3D structures vary considerably at the dimer interface and the ligand binding locales. Interestingly, each subunit of the $\mathrm{SaPanK}$ II dimer has a loop region forming a "binding cap" which closes over the binding site of the adjacent subunit[28]. Furthermore, unlike PanK $\mathrm{I}_{\mathrm{I}}$ PanK $\mathrm{III}$, and eukaryotic PanK $\mathrm{II}_{\text {II }}$ bacterial $\mathrm{SaPanK}$ II does not appear to be regulated by CoA or its thioesters[10,33]. This is consistent with results suggesting that $S$. aureus may use CoA as an antioxidant instead of glutathione[34], although subsequent literature has described bacillithiol as being involved in the redox homeostasis of $S$. aureus [35]. Sequence identity between $S a P a n K_{I I}$ and $E c P_{a n K_{I}}$ is only $13 \%$, as expected for PanKs of different Type. Remarkably, sequence identity can be very low even within Type II PanKs, with $18 \%$ identity reported for the bacterial $\mathrm{SaPanK}$ II and the mammalian Type II Mus musculus PanK1 $\beta[10]$. Finally, the only eukaryotic PanKs for which crystal structures have been reported are Homo sapiens PanK1 $\beta$ (the catalytic core of PanK1 $\alpha$ )[36] and HsPanK3[37-39].

The first crystal structure of a PanK III was that of Thermotoga maritima PanK (TmPanK $\mathrm{K}_{\text {III }}$ ) and revealed a drastically different fold compared to that of $E c \mathrm{PanK}_{\mathrm{I}}[9]$. $T m \mathrm{PanK}_{\mathrm{III}}$ is part of the ASKHA (acetate and sugar kinase/hsp70/actin) superfamily of fold[9], whereas $E c \mathrm{PanK}_{\mathrm{I}}$ belongs to the P-loop kinase superfamily[9]. Although $\mathrm{SaPanK}$ II also adopts the ASKHA fold, its structure differs significantly from those of PanK $\mathrm{K}_{\mathrm{III}}$ isoforms, with the much smaller pantothenate binding cavity of the latter providing a rationale for its restricted substrate scope[40]. Other unique biochemical traits of $\mathrm{PanK}_{\mathrm{III}}$ include the requirement for a monovalent cation such as $\mathrm{NH}_{4}{ }^{+}$or $\mathrm{K}^{+}[31]$, and no appreciable affinity for pantothenamides[30]. TmPanK $\mathrm{III}_{\mathrm{I}}$ was reported to experience negative CoA feedback, with complete inhibition at about $400 \mu \mathrm{M}$ of $\mathrm{CoA}[41]$, whereas Helicobacter pylori PanK $_{\text {III }}$ and Bacillus subtilis PanK $_{\text {III }}$ are not affected by CoA or its thioesters[30], suggesting heterogeneity in regulation within PanK types. PanK $K_{\text {III }}$ isoforms can be found across almost all phyla of bacteria[9], and typically have a high $\mathrm{K}_{\mathrm{M}}$ for ATP (PanK $\mathrm{PII}_{\mathrm{II}} \mathrm{K}_{\mathrm{M}}$ : B. anthracis $=510 \mu \mathrm{M}[42]$, B. subtilis $=3.1 \mathrm{mM}[30]$, H. pylori $=7.9-9.6 \mathrm{mM}[30,40]$, . . maritima $=6.0 \mathrm{mM}$ at $50^{\circ} \mathrm{C}[9]$ ), and little affinity for other phosphate donors[31]. Despite the ubiquity of PanK $\mathrm{III}_{\text {II }}$ enzymes in bacteria, their tight substrate specificity hinders their use in prodrug bioactivation.

\section{PPAT and DPCK}

The second and third enzymes of the CoA salvage pathway have not been as extensively studied as PanK. PPAT and DPCK are two separate proteins in bacteria, whereas in eukaryotes PPAT and DPCK are fused together into a single bifunctional enzyme called CoA Synthase 
(C) This manuscript version is made available under the CC-BY-NC-ND 4.0 license

https://creativecommons.org/licenses/by-nc-nd/4.0/

(CoASy)[43]. In bacterial systems, PPAT may be regulated by CoA via feedback inhibition[4445]. Both PPAT and DPCK were first isolated from Corynebacterium ammoniagenes (previously Brevibacterium ammoniagenes)[46]. Crystal structures are reported for PPAT and DPCK from $E$. coli[47-51] and from numerous other organisms[29,45,50,52-68], as well as for the M. musculus DPCK domain of the bifunctional PPAT/DPCK enzyme (PDB: 2F6R; no associated scientific publication). The mammalian PPAT/DPCK enzyme has the same function as the corresponding two bacterial enzymes, yet there is low homology between the bacterial and mammalian PPAT domains, and high homology between the bacterial and the mammalian DPCK domains[43]. Notably, H. sapiens PPAT/DPCK shows some tolerance for alternative substrates, as demonstrated by its use in biocatalytic reactions[69]. Bacterial, plant, and mammalian PPAT and DPCK have been described thoroughly by Leonardi et al[70].

\section{The use of PanK, PPAT and DPCK in chemoenzymatic transformations}

Examples of chemoenzymatic syntheses taking advantage of CoA biosynthetic enzymes abound, with the products often serving to study CoA-dependent enzymes[69,71-92]. The more commonly used PanK isoforms in synthetic applications are $E c \mathrm{PanK}_{\mathrm{I}}$ and $\mathrm{SaPanK} \mathrm{K}_{\mathrm{II}}$, whereas the subsequent steps typically employ EcPPAT and EcDPCK. The choice of PanK used depends on the context. $E c \mathrm{PanK}_{\mathrm{I}}[69,72]$ catalyses the phosphorylation of various pantothenate analogues, sometimes even more efficiently than with its natural substrate[78], but can be inhibited by the CoA product when used in combination with PPAT and DPCK. In contrast, $\mathrm{SaPanK}$ II is not inhibited by CoA derivatives[10] but may be inhibited by some phosphorylated pantothenamides [32]. Pantothenamides are well-tolerated by both PanK isoforms (Fig. 3), whereas pantothenate thioesters are only accepted by $S a P a n K_{I I}$ [93]. EcPanK I and $S a P a n K_{I I}$ can phosphorylate substrates containing a wide assortment of amine substituents at C-1 (pantothenate numbering, see Fig. 1), including linear alkyl chains with or without heteroatoms[94-95], alkyl chains with esters/amides/ketone/amino acid functionalities[71,73-74,76-77,79,81,96-97], bulky aliphatic moieties[72], aromatic moieties[79,81], fluorophores such as BODIPY, coumarin, and dansyl[69,79-80], and even aminoglycosides[98-99]. Use of the CoA salvage pathway for chemoenzymatic synthesis was reviewed in 2010 by Strauss et al[78].

\section{Pantothenamides as prototypical substrates of CoA biosynthetic enzymes}

First reported in 1970 by Clifton et al., $N$-substituted pantothenamides, or pantothenamides, are amides of pantothenate e.g. 1-5 (Fig. 2)[100], many of which show antibacterial, antifungal and/or antiplasmodial activity. Pantothenamides were discovered at a time when efficient antibiotics abounded and there was no incentive to pursue them all. Now that resistance is rapidly making antibiotics useless, there is interest in revisiting antimicrobials discovered long ago and abandoned. This has resulted in a rising interest for pantothenamides in the past two decades and significant efforts have been dedicated towards determining their mechanisms of action. These studies have focused mainly on three organisms, the bacteria $E$. coli and $S$. aureus, as well as the malaria-causing parasite Plasmodium falciparum, and have clearly established that pantothenamides are substrates of one or more enzymes of the CoA biosynthetic pathway. In general, the currently accepted mechanism of action of pantothenamides first involves their transformation by one or more of the CoA biosynthetic enzymes, before inhibition of one or 
more downstream enzymes. Pantothenamides are not only recognized as potential antimicrobials but have also been very useful to study PanK enzymes[27-28,94,101-104].

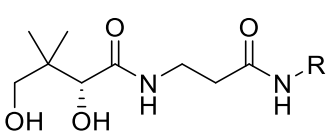

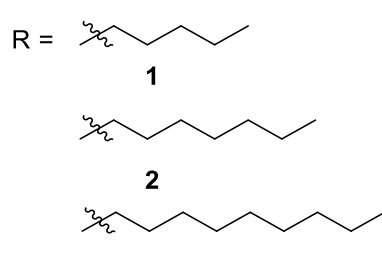

3
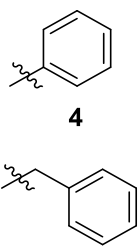

5

Figure 2: Examples of pantothenamides

In addition to mechanistic investigations, recent decades have also seen numerous medicinal chemistry studies of pantothenamides. Structure-activity relationships (SARs) of the antimicrobial activity of pantothenamides however remain complex as they must account for cell permeability, the enzymatic transformation by one or more enzymes and the numerous potential targets of the active product[105]. Pantothenamides have been modified at the primary and secondary alcohols[94,106], the geminal dimethyl group[101,105-109], the $\beta$-alanine chain[79,94,102,106,110-111], the substituents at the C-1 amide[32,79,81,94-95,100$102,106,109,112-113]$, and the amide bond itself has been replaced with other groups[103,113114]. Minor alterations are often sufficient to completely shift the spectrum of antimicrobial activity or suppress all activity.

A thorough review by Spry et al. presents pantothenate derivatives in the context of their interactions with various PanK isoforms as it relates to antimicrobial activity[115], while a more recent review by Moolman et al. discusses CoA biosynthetic enzymes as novel targets for the development of antimicrobials [116]. For most of the antimicrobial pantothenamides described, however, the mechanism of action has not been fully described and activation by CoA biosynthetic enzymes remains to be demonstrated.

\section{Substrate specificity of PanK enzymes}

To explore the substrate specificity of PanK enzymes, a variety of pantothenate derivatives have been synthesized and tested either for inhibition of pantothenate phosphorylation (competitive substrate)[94] or directly as substrates[101-103,106] (Fig. 3). These include numerous pantothenamides with the following C-1 amide modifications accepted by both $E c \mathrm{PanK}_{\mathrm{I}}$ and $\mathrm{SaPanK}$ II: linear or branched chain, with or without heteroatoms, aromatic groups, and bulky rings [94,101-102]. Substitution of either methyl group of the geminal dimethyl moiety with small or moderately bulky groups are also typically tolerated by $E c \mathrm{PanK}_{\mathrm{I}}$ and $\mathrm{SaPanK} \mathrm{K}_{\mathrm{II}}$, in contrast to removal of the methyl groups which is not[106]. Shortening the $\beta$-alanine chain is acceptable with both enzymes, whereas lengthening the $\beta$-alanine chain is not productive with $E c \operatorname{PanK}_{\mathrm{I}}[102,106]$. Methylation of the $\beta$-alanine chain or the $\mathrm{C}-1$ amide, as well as the use of amide bioisosteres at $\mathrm{C}$ 1 (e.g. thioamides, hydrazides, sulfonamides, inverted amides, and triazoles), are tolerated by both $E c \mathrm{PanK}_{\mathrm{I}}$ and $\mathrm{SaPanK} \mathrm{K}_{\mathrm{II}}[103]$. In contrast, although methylation of the secondary alcohol is fine with $E c \mathrm{PanK}_{\mathrm{I}}$, it is not for $S a \mathrm{PanK}_{\mathrm{II}}[106]$. 
(C) This manuscript version is made available under the CC-BY-NC-ND 4.0 license

https://creativecommons.org/licenses/by-nc-nd/4.0/

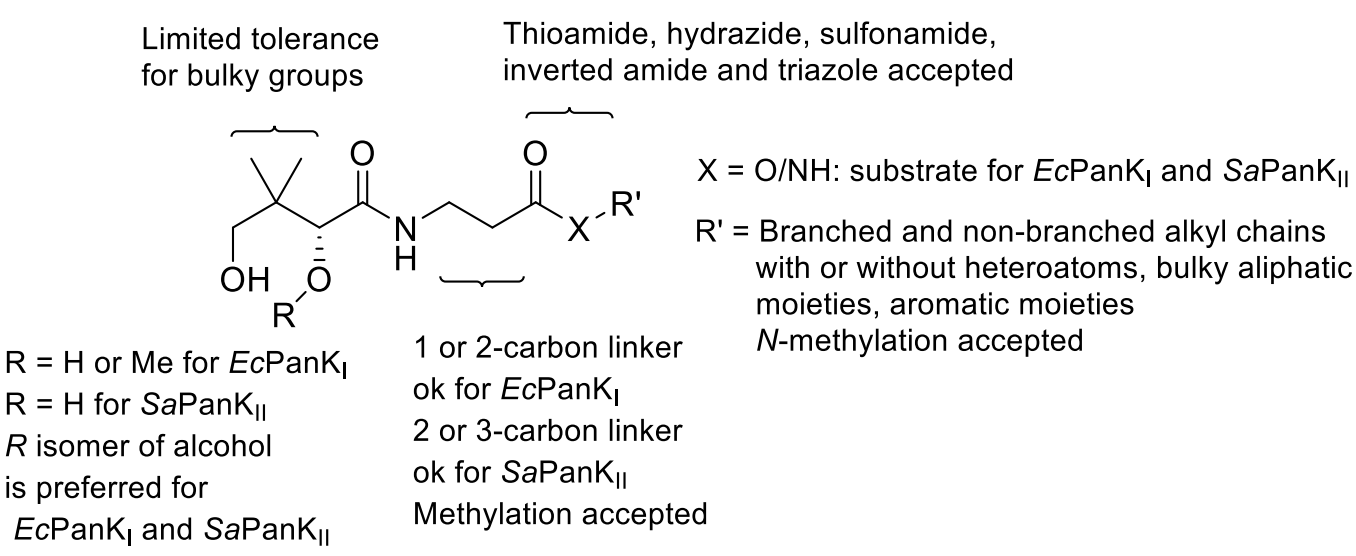

Figure 3: Substrates for EcPanK/ and SaPanK $/$ based on kinetic studies of pantothenate analogues and EcPanK/ or SaPanK $K_{l l}$

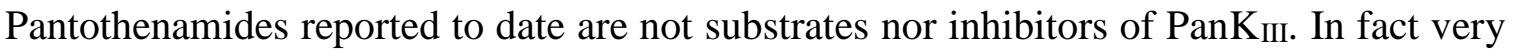

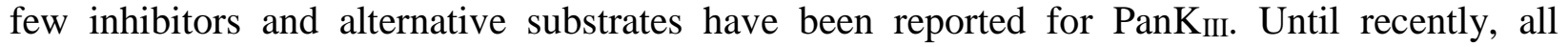
inhibitors were competing with ATP and showed weak affinity[42,117]. The first pantothenate-

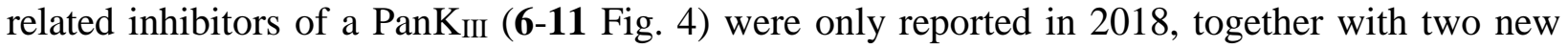
substrates $(\mathbf{1 2}, 13)$ for Pseudomonas aeruginosa PanK $_{\mathrm{III}}\left(\mathrm{PaPanK} \mathrm{K}_{\mathrm{III}}\right)[106,117]$. The $\mathrm{K}_{\mathrm{M}}$ values are greater for the new substrates $\left(\mathrm{K}_{\mathrm{M}}=12: 683 \mu \mathrm{M}\right.$, 13: $64 \mu \mathrm{M}$, Fig. 4) than for pantothenate $\left(\mathrm{K}_{\mathrm{M}}=\right.$ $20 \mu \mathrm{M})$. Nevertheless, this demonstrates some substrate promiscuity remaining to be further exploited.
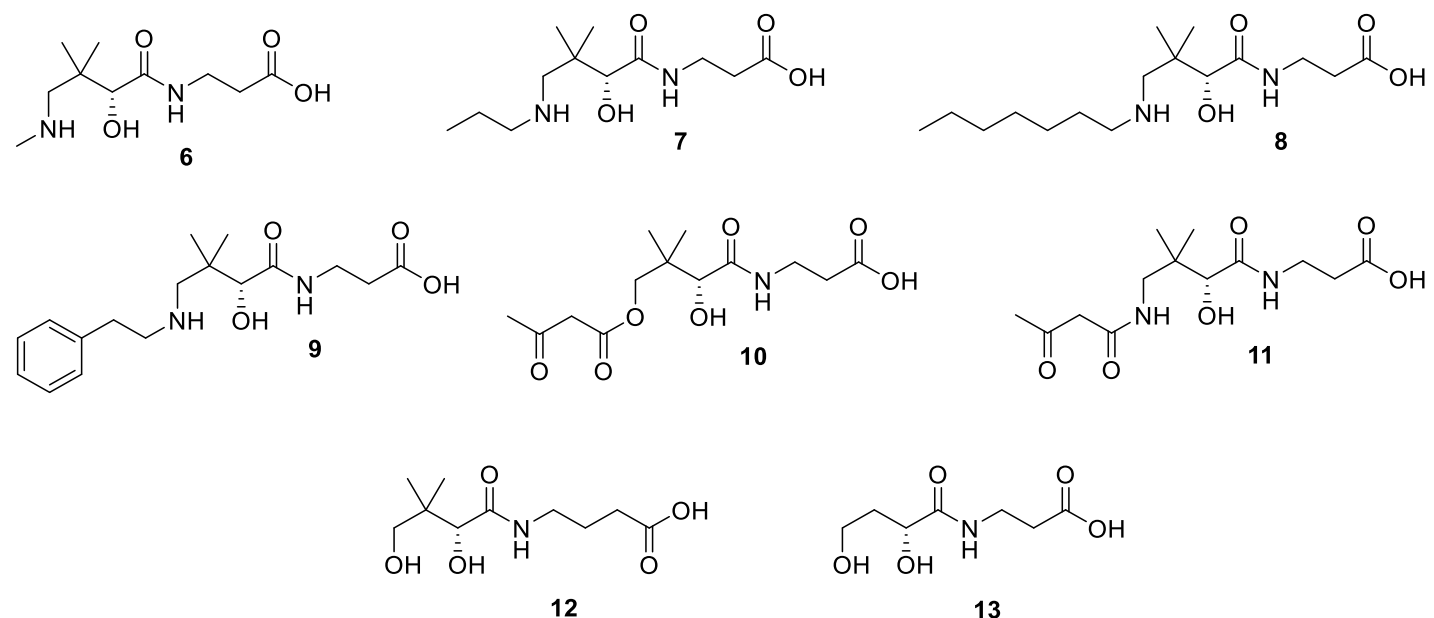

Figure 4: Pantothenate-based inhibitors and substrates for PaPanK III

In summary, $E c \mathrm{PanK}_{\mathrm{I}}$ and $\mathrm{SaPanK}$ II show similar substrate specificity, tolerating limited bulk at the geminal dimethyl position, and accepting large differences in the alkyl amine chain, even including groups as large as aminoglycosides and fluorophores (Fig. 5). EcPanK $\mathrm{I}_{\mathrm{I}}$ and $S a$ PanK $_{\text {II }}$ differ in substrate scope where thioesters are not well tolerated by $E c P_{\text {anK }}$, but are accepted by $S a \mathrm{PanK}_{\mathrm{II}}[93]$, and glycine or $\beta$-alanine is required for $E c \mathrm{PanK}_{\mathrm{I}}$ whereas $S a \mathrm{PanK} \mathrm{K}_{\mathrm{II}}$ and $P a \mathrm{PanK}_{\text {III }}$ can tolerate a one-carbon extension to $\gamma$-aminobutyrate[106]. PaPanK $\mathrm{PII}_{\text {II }}$ not known to 
tolerate any substitutions of the carboxylate, but accepts compounds lacking the geminal dimethyl group, whereas EcPanK and $S a P a n K_{I I} \operatorname{do~not[106].~}$

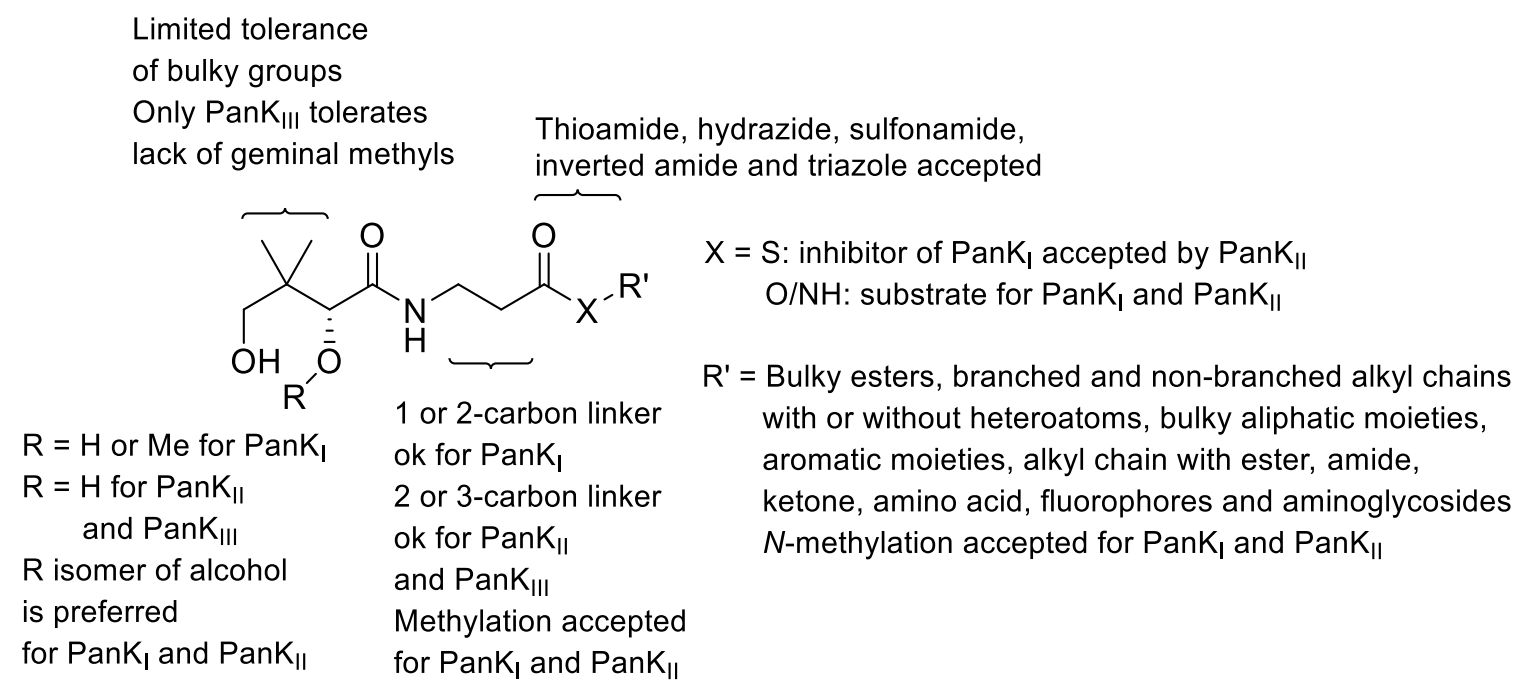

Figure 5: Summary of tolerated substitutions for substrates of bacterial Pank enzymes based on kinetic studies and chemoenzymatic transformations

The substrate specificity of eukaryotic PanKs has not been as thoroughly explored as that of bacterial isoforms. In a study by Virga et al., the PanKs from Aspergillus nidulans (AnPanK $\mathrm{II}_{\text {) }}$ and $M$. musculus $(M m P a n K 1 \alpha)$ were evaluated for their activity towards several pantothenamides[94], and found to tolerate a broad range of structural variations (Fig. 6). The substrate preference was evaluated as a relative inhibition of pantothenate phosphorylation with the assumption that the inhibition was due to the test compound behaving as a substrate. This remains to be confirmed as the compounds may also be inhibitors. Crystallographic structures of

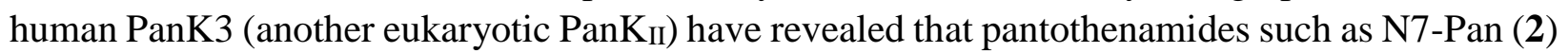
are PanK3 ligands [38]. In a different study, HoPan (12) was found to inhibit MmPanK1 $\alpha$ after being first phosphorylated by the enzyme[118]. A similar product-inhibition mechanism has also been suggested for $\mathrm{SaPanK}$ II, which crystallized with phosphorylated N7-Pan [32]. Overall, this speaks strongly in favour of further studies of eukaryotic PanK.
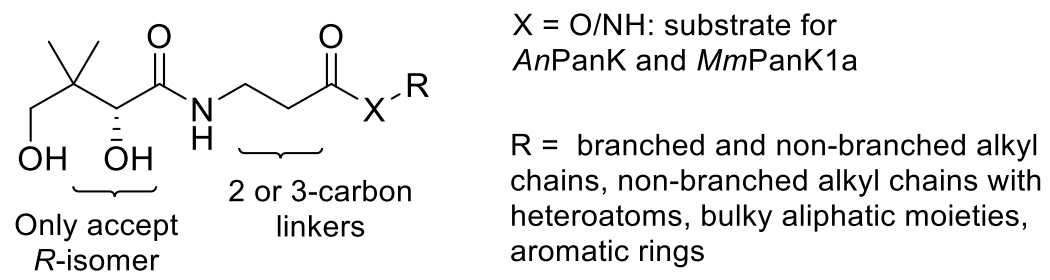

Figure 6: Tolerated substitutions for AnPanK and MmPanK1 $\alpha$ based on substrate competition substrates

\section{Mechanism of action of pantothenamides in $E$. coli}

In E. coli, a PanK $\mathrm{I}_{\mathrm{I}}$-expressing organism, the product of pantothenamide phosphorylation is further transformed by PPAT and DPCK to generate the corresponding CoA anti-metabolite[119]. In particular, pantothenamides N5-Pan (1) and N7-Pan (2) were shown to be converted to 
ethyldethia-CoA (14) and butyldethia-CoA (15) (Fig. 7), respectively, faster than pantothenate is turned to CoA[119-120]. In E. coli, compounds 14 and 15 were demonstrated to replace CoA as the co-substrate of acyl carrier protein (ACP) synthase, leading to the formation of a thiol-lacking, inactive ACP (crypto-ACP), thereby negatively affecting fatty acid biosynthesis and bacterial proliferation[120]. In support of this hypothesis, supplementation of the growth medium with exogenous fatty acids restored viability to bacteria exposed to 1 or 2[120]. It was later established that the rescue of bacterial growth by fatty acids supplementation was only partial (in contrast to the complete rescue of growth resulting from addition of fatty acids during exposure to the fatty acid synthesis inhibitor cerulenin), suggesting that pantothenamides $\mathbf{1}$ and $\mathbf{2}$ may have other targets besides fatty acid synthesis[121].
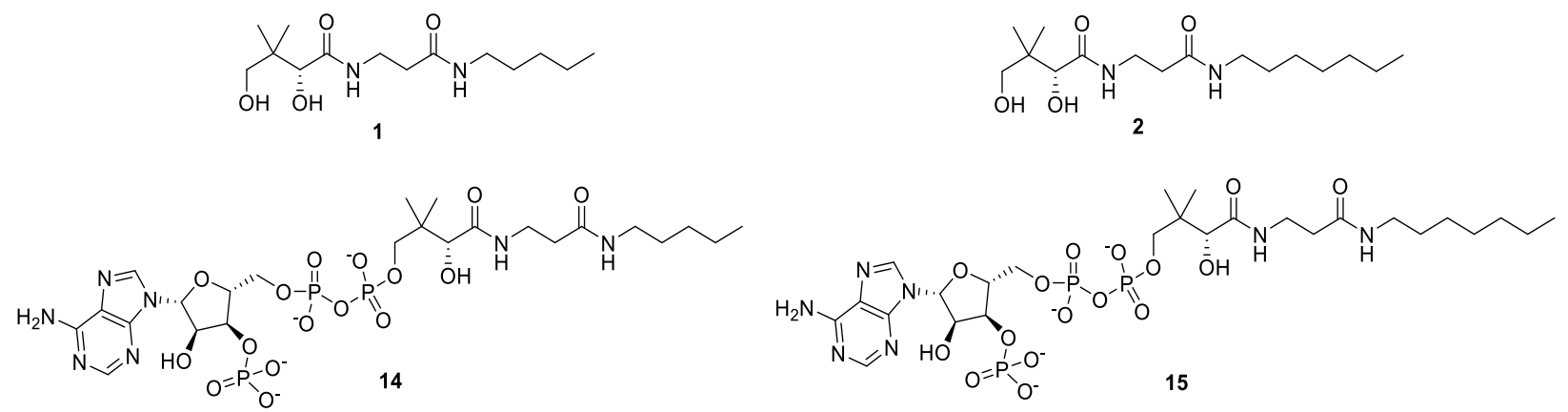

Figure 7: N5-Pan (1) and N7-Pan (2) and their antimetabolites after bioactivation by PanK, PPAT, and DPCK

Further experiments were performed by Thomas and Cronan in which the nutrient supply was limited to tease out other effects of the CoA antimetabolites on bacterial growth[121]. These studies demonstrated that CoA stores were being depleted in the presence of $\mathbf{1}$, and that cryptoACP can be hydrolysed back to apo-ACP in cellulo[121]. To further complicate matters, not all pantothenamides known to yield crypto-ACP species are toxic to E. coli[95], implying again that other factors may be involved in the antibacterial activity of pantothenamides. Recent studies looking at the mode of action of $\mathbf{1}$ in E. coli suggest that its resulting CoA antimetabolite (14) may also affect aspartate decarboxylation by PanD (within the pantothenate biosynthetic pathway) by binding to its regulatory protein PanZ[122]. AcCoA is known to bind to the PanD-PanZ complex and inhibit the production of pantothenate; this effect may be reproduced by metabolite $\mathbf{1 4}$ which binds to PanZ with equal affinity as AcCoA[122-123]. Interestingly, replacing the E. coli wild type PanD with a PanD variant unable to interact with PanZ eliminates regulation by CoA or 14[122]. Moreover, the MIC of 1 was found to be 30-fold greater towards an E. coli strain harboring this PanD variant than cells expressing wild type PanD $(60 \mu \mathrm{g} / \mathrm{mL}$ versus $2.3 \mu \mathrm{g} / \mathrm{mL})[122]$. In summary, the collective interferences of the CoA antimetabolites are likely what lead to the growth inhibition of E. coli (Fig. 8). 


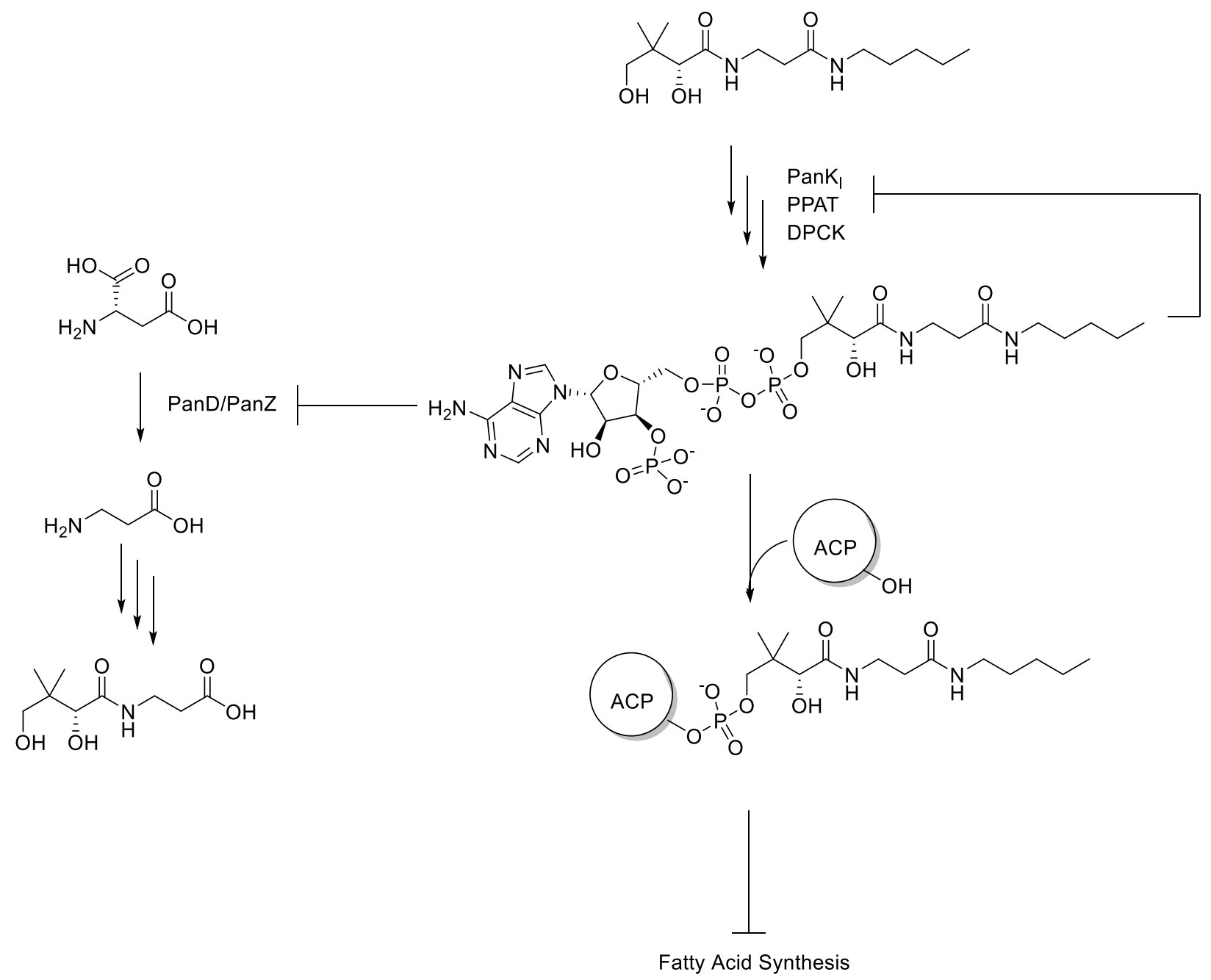

Figure 8: Antibacterial mechanism of action of pantothenamides, such as N5-Pan (1), in E. coli (a PanK $K_{l}$-expressing bacterium)

\section{Mechanism of action of pantothenamides in S. aureus}

$\mathrm{SaPanK}$ II is known to phosphorylate pantothenamides such as $\mathbf{1}$, leading to a bacteriostatic effect on $S$. aureus. A recent study has demonstrated that once transformed by $S a$ PanK $K_{\text {II, }}$ the corresponding phosphorylated pantothenamides have very high affinity for the enzyme, dramatically reducing its rate. This suggests a mechanism of action in $S$. aureus involving first phosphorylation of the pantothenamide by $S a$ PanK $K_{I I}$ followed by product inhibition of this essential enzyme (Fig. 9)[32]. The study also revealed an important correlation between slow pantothenamide turnover and inhibition of $S a \mathrm{PanK}_{\text {II. }}$. Together these results corroborate earlier crystallographic data suggesting that the amide substituent of pantothenamides can form additional interactions with the enzyme to stabilize the complex and reduce the rate of release of the phosphorylated pantothenamide product by $S a \operatorname{PanK}_{\mathrm{II}}[28]$. 
(C) This manuscript version is made available under the CC-BY-NC-ND 4.0 license

https://creativecommons.org/licenses/by-nc-nd/4.0/

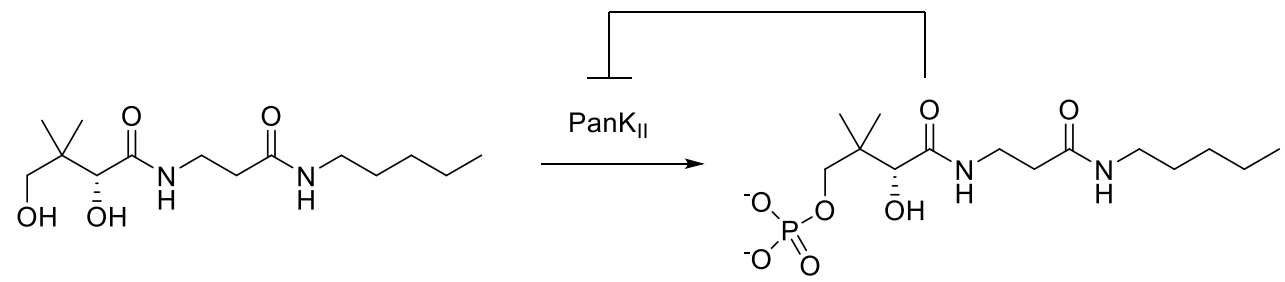

Figure 9: Proposed mode of action for bioactivated pantothenamides such as N5-Pan (1) in S. aureus (a PanK II-expressing bacterium)

\section{Mechanism of action of pantothenamides in P. falciparum}

The bioactivation of molecules via CoA biosynthetic enzymes expands beyond bacteria, with a few reports of pantothenate derivatives shown to be transformed by enzymes from $P$. falciparum. Recognised as essential during infection[124-128], the CoA biosynthetic pathway of Plasmodium spp. has been suggested as a novel target for the discovery of antimalarials[129]. In 2013, Spry et al. demonstrated that pantothenamides can inhibit the growth of blood stage $P$. falciparum, but only when the culture medium used was aged[130]. This was explained by the presence of pantetheinases, also known as vanins, in fresh serum. As discussed further below, these enzymes produce pantothenate from pantetheine and other pantothenamides.

Notably, P. falciparum PanK (PfPanK II) has yet to be isolated or heterologously expressed. PfPanK $\mathrm{K}_{\mathrm{II}}$ activity and inhibition are typically measured from $P$. falciparum lysates with added $\left[{ }^{14} \mathrm{C}\right]$ pantothenate (26, Fig. 11) and monitoring the formation of $\left[{ }^{14} \mathrm{C}\right] 4^{\text {'- }}$ phosphopantothenate[131]. This assay does not differentiate alternative substrates from inhibitors since molecules which act as PanK substrates by competing with pantothenate appear to inhibit the enzyme. Several pantothenamides (1, 16-20, Fig. 10) were found to inhibit pantothenate phosphorylation by $P f \mathrm{PanK}_{\mathrm{II}}$ at micromolar concentrations whereas antiplasmodial activity for the same compounds is observed at nanomolar concentrations[132]. This large difference between enzyme and growth inhibition suggests that PfPanK $\mathrm{II}_{\mathrm{II}}$ may not be the main target of these compounds in $P$. falciparum.

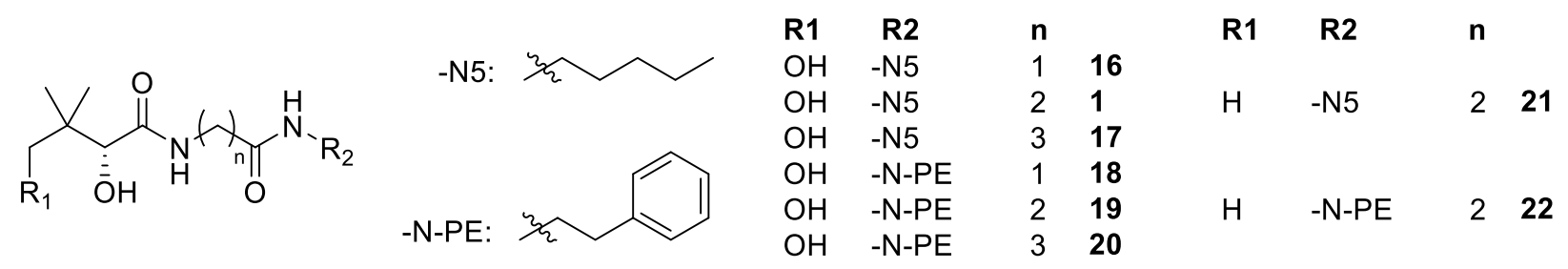

Figure 10: Structure of pantothenamides 1, 16-22. Note: 21 and 22 were tested as racemic mixtures.

The mechanism of action was further probed using pantothenamides 23, 24, and 25 with varying lengths of the $\beta$-alanine chain, and radiolabelled 26-32 (Fig. 11)[132]. Interestingly, while 27 and 28 require the pantothenic acid transporter for activity, 29-32 do not, suggesting the involvement of different uptake mechanisms for pantothenate derivatives in $P$. falciparum[132]. The results also suggest that pantothenamides do not interfere with pantothenate transport[132]. 
<smiles>[R]NC(=O)CNC(=O)[C@@H](O)C(C)(C)CO</smiles>

23<smiles>[R]NC(=O)CCNC(=O)[C@H](O)C(C)(C)CO</smiles>

24<smiles>[R]NC(=O)CCCNC(=O)C(O)C(C)(C)CO</smiles>

25<smiles>CC(C)(CO)[C@H](O)C(=O)NCCC(=O)O</smiles>
26<smiles>CCCC[C@H](C)NC(=O)CNC(=O)[C@@H](O)C(C)(C)CO</smiles>

27<smiles>CCCCC[C@H](C)NC(=O)CCNC(=O)[C@@H](O)C(C)(C)CO</smiles>

29<smiles>CCCCCCNC(=O)CCCNC(=O)C(O)C(C)(C)CO</smiles>

31<smiles>C[C@H](NC(=O)CNC(=O)[C@H](O)C(C)(C)CO)c1ccccc1</smiles>

28<smiles>CC(C)(CO)[C@@H](O)C(=O)NCCC(=O)NCc1ccccc1</smiles><smiles>C[C@H](NC(=O)CCCNC(=O)[C@H](O)C(C)(C)CO)c1ccccc1</smiles>

32

Figure 11: Structure of compounds 23-32 with the position of ${ }^{14} \mathrm{C}$ atoms identified (*)

Interestingly, whereas the deoxy-derivatives 21 and 22 (Fig. 10) were inhibitors of pantothenate phosphorylation $(>100 \mu \mathrm{M}$ and $11 \mu \mathrm{M}$ respectively), they did not show significant antiplasmodial activity[132], further confirming that PanK inhibition may not be responsible for the antiplasmodial activity of pantothenamides. This is in contrast to similar experiments using $\mathrm{SaPanK}$ II where 21 was found to effectively inhibit pantothenate phosphorylation and also exhibit antistaphylococcal activity[103]. Overall this is consistent with the mechanism of action of pantothenamides differing between $S$. aureus and $P$. falciparum, and suggests that the targets of pantothenamides in P. falciparum are likely downstream of PanK (Fig. 12). 
(C) This manuscript version is made available under the CC-BY-NC-ND 4.0 license https://creativecommons.org/licenses/by-nc-nd/4.0/
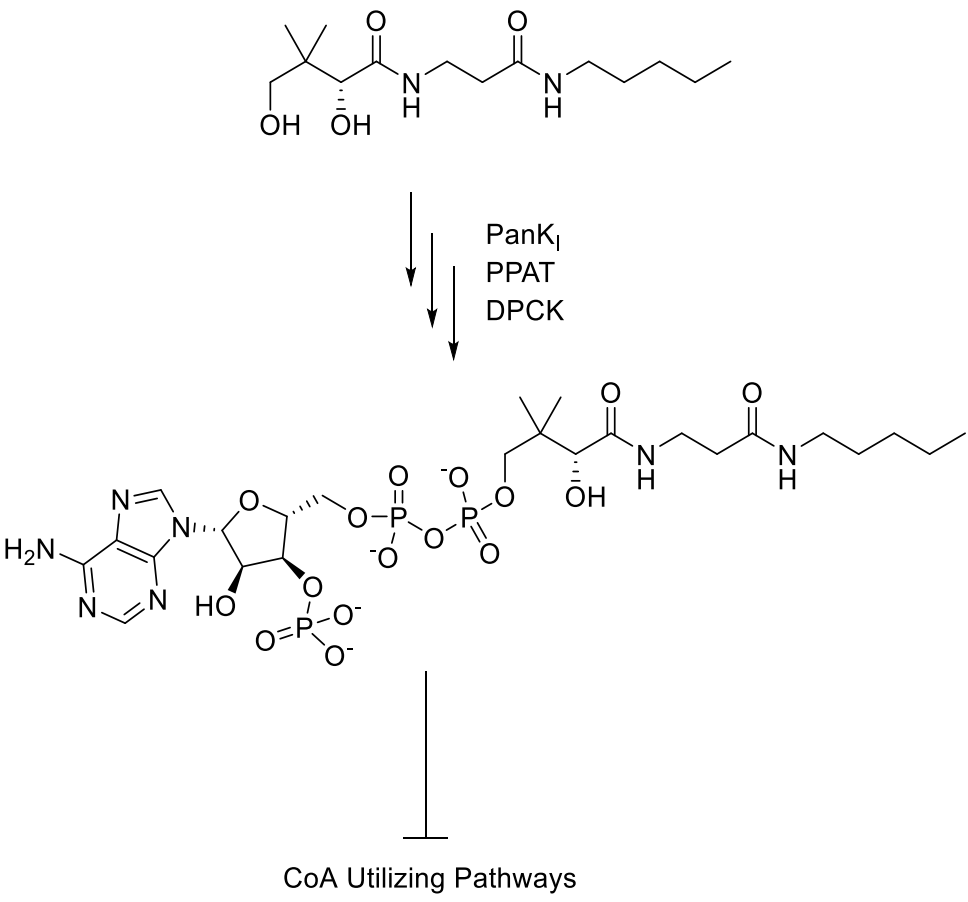

Figure 12: Proposed mode of action for pantothenamides, such as N5-Pan (1), in P. falciparum (expressing PanK II).

In a recent report, the $\alpha$-methylated pantothenamide 36 (Fig. 13) (previously reported by Macuamule et al.)[133] was found to compete with pantothenate for phosphorylation by Cab1 (a yeast PanK) at mid-micromolar concentrations, and the authors concluded that PanK inhibition was the cause of antiplasmodial activity, even though they reported $P$. falciparum growth inhibition at mid-nanomolar concentrations[111]. A more recent study by Tjhin et al. used a combination of methods including PfPanK $\mathrm{II}$ inhibition studies, in cellulo metabolism characterization and resistant mutants, to further investigate the mechanism of action of $\mathbf{3 5}$ and $\mathbf{3 6}$ in P. falciparum (Fig. 13)[134]. The authors used pantothenol (33) and CJ-15,801 (34) to generate resistant strains. The antiplasmodial activity of $\mathbf{3 3}$ and $\mathbf{3 4}$ is believed to arise from the transformation by PanK only, or PanK and PPCS, with the product inhibiting PPCS[134-135]. Interestingly, the mutants resistant to $\mathbf{3 3}$ or $\mathbf{3 4}$ exhibited different sensitivity profiles towards $\mathbf{3 5}$ and 36, including two mutants that became hypersensitive to $\mathbf{3 5}$ and one hypersensitive to $\mathbf{3 6}$. Moreover, 35 was reported to be fully transformed to the corresponding CoA derivative in $P$. falciparum[134]. The authors concluded that $\mathbf{3 5}$ and $\mathbf{3 6}$ exhibit a different mechanism of action than 33 and 34, with the latter two inhibiting PPCS after biotransformation, whereas the former two are bioactivated to the corresponding CoA derivatives, which may inhibit various CoAutilising enzymes. 
(C) This manuscript version is made available under the CC-BY-NC-ND 4.0 license

https://creativecommons.org/licenses/by-nc-nd/4.0/<smiles>CC(C)(CO)[C@H](O)C(=O)NCCCO</smiles>

33

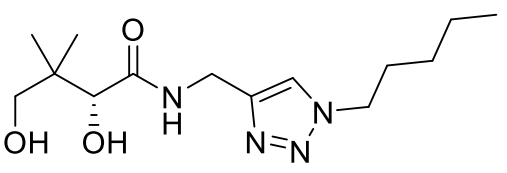

35<smiles>CC(C)(CO)[C@H](O)C(=O)N/C=C/C(=O)O</smiles>

34<smiles>C[C@@H](CNC(=O)[C@@H](O)C(C)(C)CO)C(=O)NCCc1ccccc1</smiles>

36

Figure 13: Pantothenol (33) and $\mathrm{CJ}-15,801$ (34) were used to force resistance in $\mathrm{P}$. falciparum and the resistant mutants were challenged with the potent antiplasmodials 35 and 36

\section{Exploitation of CoA biosynthetic enzymes as a new strategy for the in cellulo assembly of enzyme inhibitors}

Whereas mechanistic studies suggest that pantothenamides are bioactivated by one or more of the CoA biosynthetic enzymes, at least in E. coli and in P. falciparum the resulting CoA antimetabolites likely have multiple targets, and hence structure-based design (i.e. inhibitor design using the structure of the target protein) is intangible, leaving ligand-based design as the main approach available. In contrast, a few examples where the CoA biosynthetic pathway is used for the bioactivation of inhibitors of a specific enzyme have also been reported. The first case was published in 2012 by Vong et al. and allowed researchers to overcome bacterial cell penetration issues[98]. Once the prodrugs 37-41 (Fig. 14) were transformed into the corresponding CoA derivatives in Enterococcus faecium, the molecules inhibited the aminoglycoside resistancecausing enzyme aminoglycoside $N$-6'-acetyltransferase (AAC(6')), and resensitized the intrinsically resistant bacterium to aminoglycosides[98].
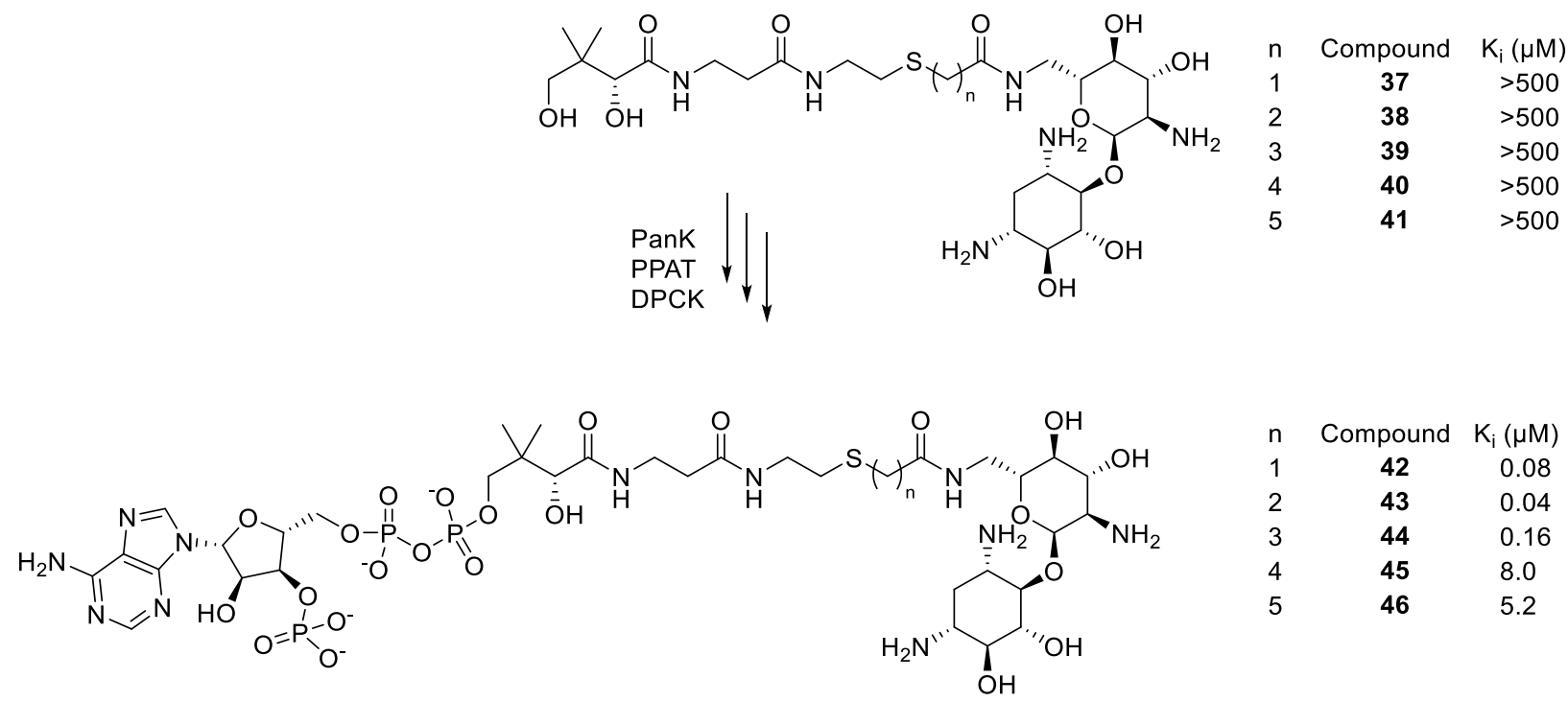

Figure 14: Bioactivation of pantothenate-aminoglycoside derivatives by CoA biosynthetic enzymes into bisubstrate inhibitors of $A A C\left(6^{\prime}\right)$. Ki values are given for inhibition of $\mathrm{E}$. faecium $A A C\left(6^{\prime}\right)$. 
A widespread mechanism of aminoglycoside antibiotic resistance involves the expression of $\mathrm{N}$-acetyltransferases by bacteria[136]. These enzymes use AcCoA to selectively acetylate aminoglycosides at one or more specific sites, resulting in molecules with greatly reduced affinity for the ribosome 16S RNA, aminoglycoside's target. The authors had previously identified several amide-linked aminoglycoside-CoA bisubstrates (42-44 among others) as nanomolar inhibitors of E. faecium AAC(6')[137], and micromolar inhibitors of Salmonella enterica AAC(6')[138]. These highly charged, large molecules were however not expected to penetrate bacteria, in part due to the CoA moiety. It was envisioned that the smaller pantothenate derivatives, compounds 37-41, which do not inhibit AAC(6')[139] and have no antibacterial activity[137], might penetrate bacterial cells before being transformed into the corresponding bisubstrate inhibitors $\mathbf{4 2 - 4 6}$ by CoA biosynthetic enzymes in bacteria[137]. As expected, the aminoglycoside-pantothenate derivatives 37-41 were inactive on their own but 38-41 potentiated the activity of kanamycin A towards aminoglycoside-resistant E. faecium. The in cellulo activity was optimal with a twocarbon linker (38), contrary to the trend observed with bisubstrate AAC(6') inhibitors, which show similar activity for one- or two-carbon linkers (42 and 43), and decreasing activity as the length of the linker is increased (Fig. 14)[139]. In contrast, bioactivation by CoA biosynthetic enzymes was more efficient with longer linkers, and negligible when the linker was one carbon-long[98], suggesting that the most active molecule in cellulo may offer the best compromise between the rate of bioactivation and $\mathrm{AAC}\left(6^{\prime}\right)$ inhibition potency. Compound 38 resensitized E. faecium to the effect of several aminoglycosides including tobramycin, kanamycin A, and ribostamycin, and was also effective towards an AAC(6')-producing E coli strain, as well as clinical Enterococcus strains resistant to both vancomycin and aminoglycosides[98-99]. Further studies combining time-kill data and metabolomics established that the mechanism of action in E. faecium for compound $\mathbf{3 8}$ may involve $\mathrm{AAC}\left(6^{\prime}\right)$ inhibition by more than one intermediates along the bioactivation pathway, with the product of $\mathrm{PanK}_{\mathrm{I}}+\mathrm{PPAT}$, i.e. compound 48 (Fig. 15), contributing the larger inhibitory effect[99]. Although the full bisubstrate 43 (product of PanK $\mathrm{I}_{\mathrm{I}}+\mathrm{PPAT}+\mathrm{DPCK}$ ), which is the most potent AAC(6') inhibitor of the series, did not accumulate over time, concentration of the intermediate 48, which compared to 43 only lacks one phosphate group at the ribose 3'-OH and shows weaker AAC(6') inhibition, rose significantly over time. Compound 47 also accumulated to some extent, but due to its weaker AAC(6') inhibitory activity, is only expected to contribute a minor portion of the observed overall activity. 

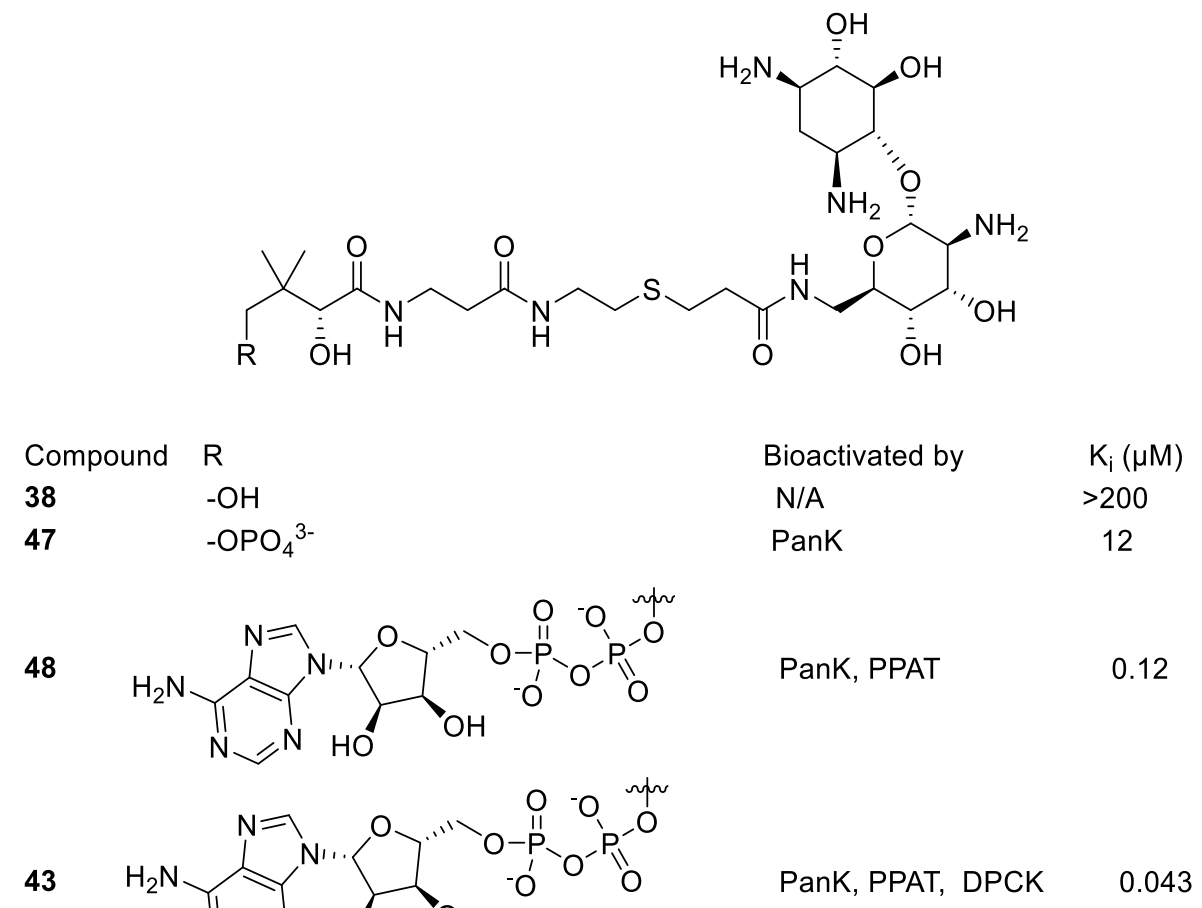

43

PanK, PPAT, DPCK $\quad 0.043$

Figure 15: Compound 38 and all intermediates of its bioactivation by the CoA biosynthetic enzymes PanK, PPAT and DPCK. Ki values are given for inhibition of $\mathrm{E}$. faecium $A A C\left(6^{\prime}\right)$.

In a second example, Hammerer et al. reported taking advantage of the CoA biosynthetic pathway to generate an itaconate degradation inhibitor in cellulo[97]. The molecule was found to resensitize Salmonella enterica serovar Typhimurium to itaconate, an important macrophage metabolite with antimicrobial (via inhibition of isocitrate lyase or Icl)[140-142] and immunomodulatory activities[143-151]. S. Typhimurium has a pathway dedicated to the degradation of itaconate which is required for persistence in macrophages[152], to promote pathogenicity[153], and for causing mammalian infections[154-155]. Itaconate degradation consists of three steps (Fig. 16): the coupling of itaconate to CoA to form an itaconyl-CoA thioester facilitated by itaconate CoA transferase (Ict), followed by regioselective water addition across the double bond to generate $(S)$-citramalyl-CoA catalyzed by itaconyl-CoA hydratase (Ich), and finally cleavage of the molecule into AcCoA and pyruvate by $(S)$-citramalyl-CoA lyase $(\mathrm{Ccl})[153,156]$. 
(C) This manuscript version is made available under the CC-BY-NC-ND 4.0 license https://creativecommons.org/licenses/by-nc-nd/4.0/

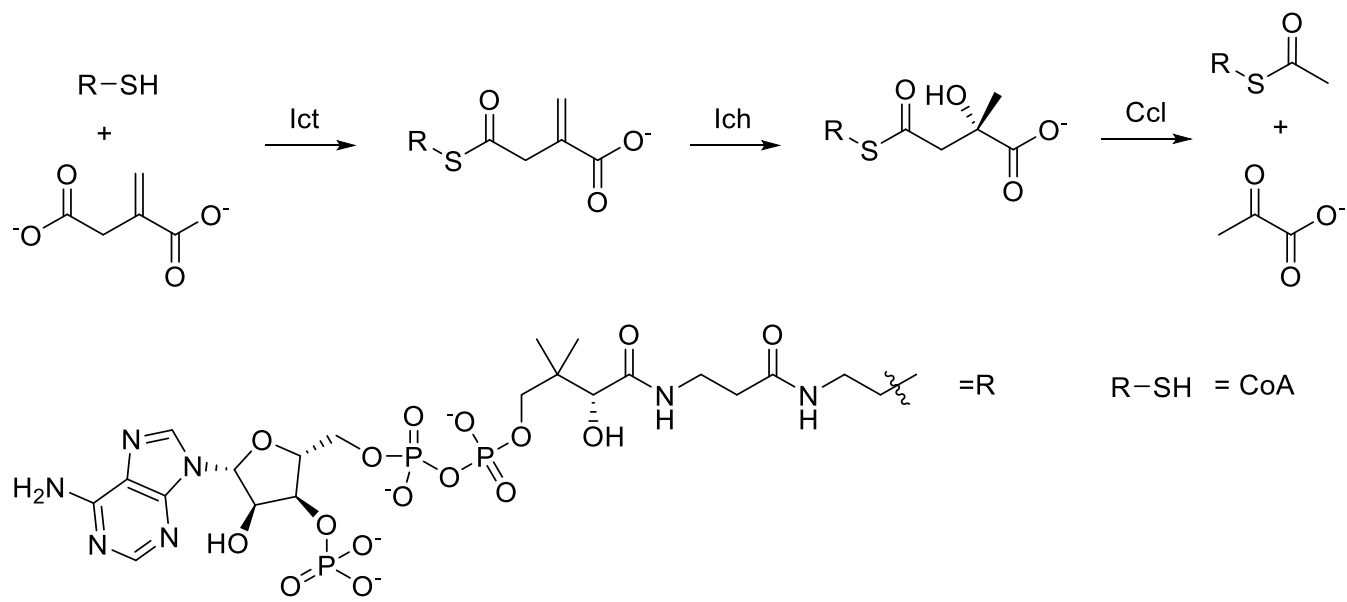

Figure 16: Degradation of mammalian itaconate by the bacterial enzymes Ict, Ich, and Ccl

Overall this process transforms a mammalian antimicrobial into food[153]. In the absence of crystal structures for any of these 3 enzymes, Hammerer et al. set out to inhibit Ich by mimicking its substrate itaconyl-CoA with compounds such as $\mathbf{5 0}$ (Fig. 17). Here again, it was envisaged to use the CoA biosynthetic pathway to avoid cell permeation issues generally associated with CoA derivatives. The corresponding precursor, compound 49 was inactive when used alone but was found to resensitize $S$. Typhimurium to the lethal effect of itaconate. The pantothenate derivative 49 was shown to be transformed into the corresponding CoA derivative both in vitro using $E c$ PanK $_{\mathrm{I}}, E c \mathrm{PPAT}$ and EcDPCK, and in $S$. Typhimurium cells which express a PanK $\mathrm{I}_{\mathrm{I}}$ 97]. Together these studies demonstrate the utility of CoA biosynthetic enzymes in the bioactivation of inhibitors in bacteria.

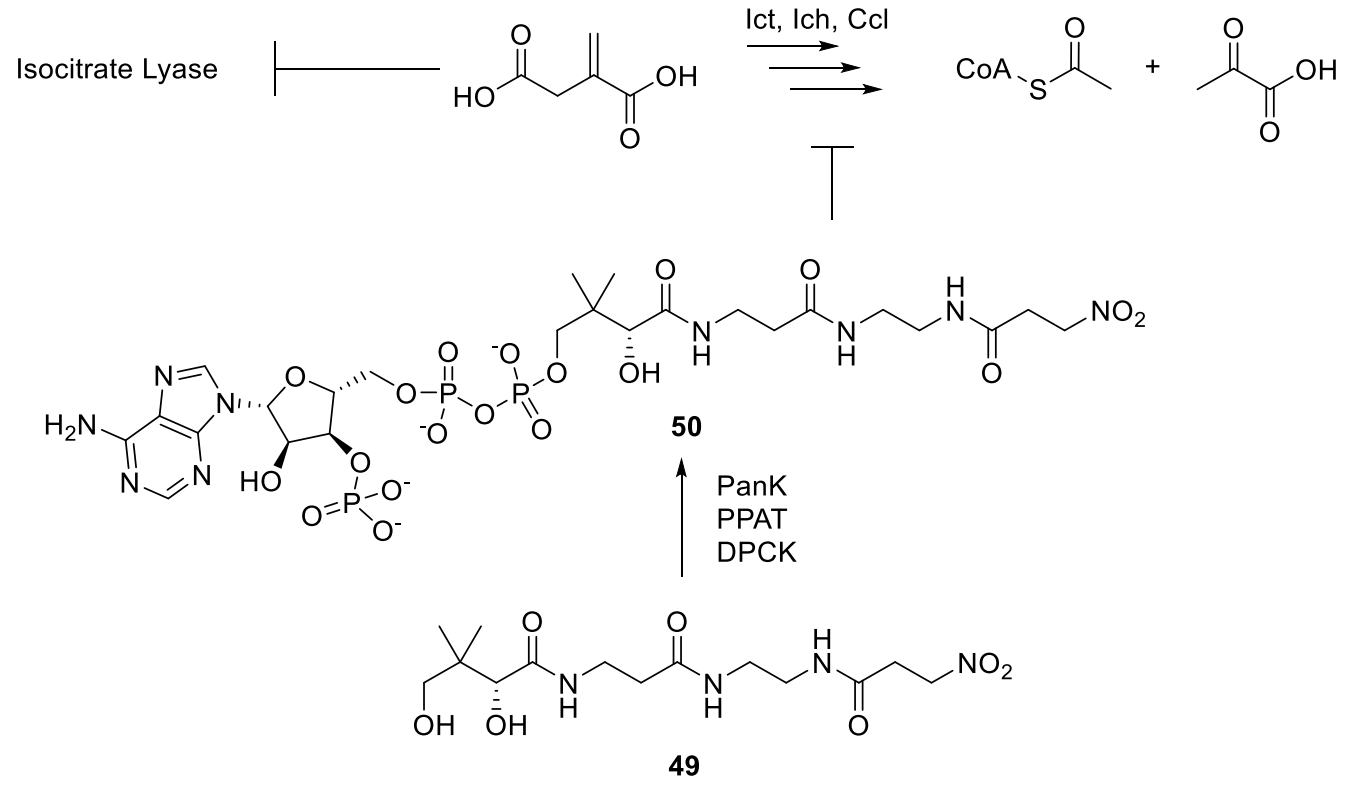

Figure 17: Inhibition of itaconate degradation by pantothenate derivative 49 transformed in cellulo to 50 by the CoA biosynthetic enzymes PanK, PPAT, and DPCK. 
(C) This manuscript version is made available under the CC-BY-NC-ND 4.0 license

https://creativecommons.org/licenses/by-nc-nd/4.0/

\section{The problem of pantetheinases}

As mentioned above, amides of pantothenate are typically not stable in serum due to the presence of pantetheinases, or vanins, which rapidly hydrolyse the molecules to pantothenate and the corresponding amine. For example, $N$-isobutyl pantothenamide (51) was $>99 \%$ hydrolysed to 52 and 53 within approximately 4 hours of incubation in a fresh, serum-containing, growth medium[130] (Fig. 18). This lack of stability is a major limiting factor for use of pantothenamides in vivo and is also problematic when serum is used in an assay, such as for blood stage antiplasmodial activity measurements. In a series of experiments to estimate the intrinsic activity of pantothenamides towards $P$. falciparum, Spry et al.[130] compared the activity of blood-stage parasites maintained in either fresh or aged (i.e. heat-treated to denature pantetheinases) growth media. Most pantothenamides were found to be more potent when tested in heat-treated media rather than fresh media[130], whereas pantothenol (33), which lacks the labile amide, retained equal activity under both conditions[130].

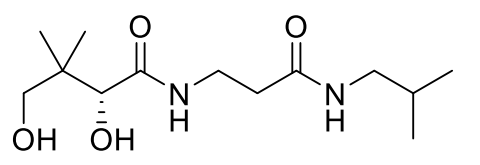

51

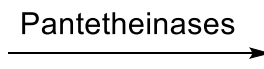

$\mathrm{OH} \quad \overline{\mathrm{O}} \mathrm{H}$<smiles>CC(C)CNCCC(=O)[O-]</smiles>

52

53

Figure 18: Hydrolysis of pantothenamide 51 by pantetheinases

To minimize the degradation of pantothenamides during such assays, Jansen et al. reported a series of pantetheinase inhibitors, including 54-59 (Fig. 19)[157]. The co-incubation of pantetheinase inhibitors with pantothenamides was found to restore pantothenamide activity against $S$. aureus and $E$. coli when the bacteria were cultured in serum-containing media, thus demonstrating the use of pantetheinase inhibitors as a viable strategy to overcome the poor serum stability of most pantothenamides[158].

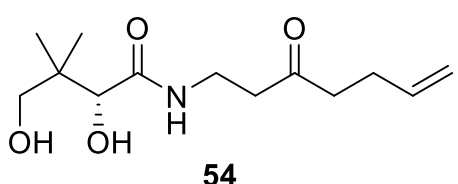

$\overbrace{\mathrm{O}=\mathrm{OH}}^{\mathrm{O}}$

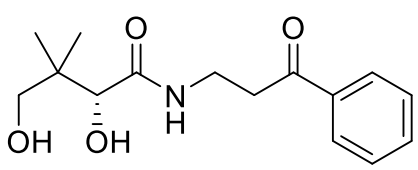

55

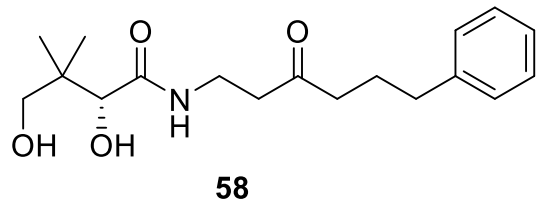<smiles>CC(C)(CO)[C@H](O)C(=O)NCCC(=O)Cc1ccccc1</smiles>

56<smiles>CC(C)(CO)[C@H](O)C(=O)NCC[C@@H](O)Cc1ccccc1</smiles>

59

Figure 19: Pantetheinase inhibitors

An alternative strategy to overcome this instability issue is to synthesize pantothenamide derivatives and analogs that are poor pantetheinase substrates. One modification that proved successful to improve the half-life of pantothenamides in serum is $\alpha$-methylation of the labile amide bond. This significantly reduced the rate of pantothenamide hydrolysis from complete hydrolysis after 24 hours for the parent compound 19, to only $25 \%$ hydrolysis for the 
corresponding $\alpha$-methylated pantothenamide 36[133]. Compound 36 was stable enough to allow experiments in mice, which showed that the pantothenamide is non-toxic and is able to control plasmodial infections[111]. When administration of the pantothenamide was halted; however, the plasmodial infection returned and progressed rapidly, demonstrating the cytostatic - as opposed to cytocidal - effect of this pantothenamide derivative[111].

Several other alterations to the pantothenamide structure have been shown to improve serum stability (Fig. 20), including substitutions at the geminal dimethyl group[75,107], modifying the length of the $\beta$-alanine linker (e.g. 16-18, 20)[132,159], and replacing the labile amide group with bioisosteric moieties [103,113-114]. Swapping the labile amide with a 1,4-disubstituted1,2,3-triazole ring not only improved serum stability, but also dramatically enhanced antiplasmodial activity, and led to molecules that are non-toxic to human cells[113-114]. This is however not the norm, and modifications which increase stability often reduce biological activity. Alterations of the pantothenamide structure was further probed by Barnard et al. with the aim of improving stability while maintaining antibacterial activity[104]. Replacement of the labile amide with various bioisosteres, methylation of the amide or $\beta$-alanine chain, and deoxygenation or phosphorylation of the primary alcohol group, all translated into compounds stabilized against pantetheinases[104]. Although, when the aforementioned substitutions were made on N7-Pan, only reversing the amide, 4'-deoxygenation, or substitution to the 4'-amine led to compounds with antibacterial activity towards $E$. coli, while only reversing the amide, $\beta$-methylation of $\beta$-alanine, 4'-deoxygenation, or 4'-phosphorylation yielded compounds with antistaphylococcal activity[103]. Modifications at the geminal dimethyl group[107-108] or replacing the labile amide with a triazole ring[113] both improved stability against pantetheinases while retaining or improving antiplasmodial activity. A recent report by Jansen et al. has shown that an inversion of the amide bond leads to an analog which retains some antimicrobial activity while resisting hydrolysis by pantotheinase[104].

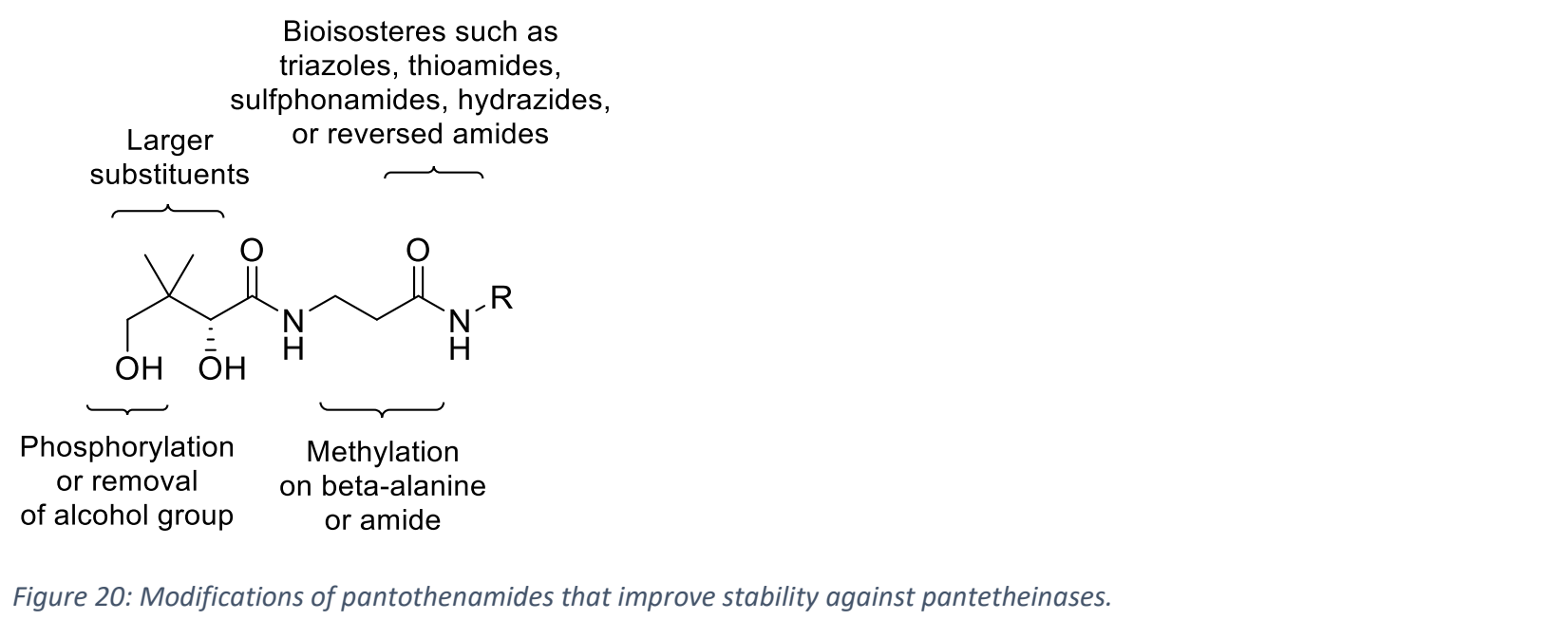

\section{Conclusions and perspective}


Bioactivation of molecules by CoA biosynthetic enzymes has been demonstrated in several microbes including E. coli, S. aureus, P. falciparum, E. faecium and $S$. Typhimurium. Advantages of this bioactivation pathway include a high tolerance towards a broad scope of pantothenate analogs, a high yield, the possibility for selective activation in bacteria, and even selectivity for one strain over another. Importantly, this approach can provide a means to circumvent cell permeability issues and inhibit CoA-dependent enzymes in cellulo. For this bioactivation mechanism to be effective in vivo or in plasma-containing growth media, however, the molecules must be stable to pantetheinases. Strategies to improve serum stability include using pantothenamides in combination with a pantetheinase inhibitor, methylation around the amide $(\alpha-$ methylation, $\beta$-methylation or $N$-methylation), replacing a methyl group with a larger substituent or substituting the labile amide with a non-hydrolysable bioisostere. Although not demonstrated yet, bypassing PanK by incorporating a 4'-phosphate group into the precursor, or a 4'-phospho ester to help with cell penetration since for example bacteria may not uptake 4'phosphopantetheine [160], may be a strategy to allow bioactivation in eukaryotic cells or

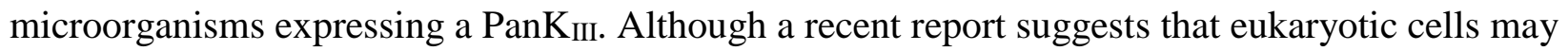
transport and employ 4'-phosphopantetheine in the biosynthesis of CoA[161], the possibility of partial extracellular dephosphorylation has not been fully eliminated. Srinivisan et al. observed 4'phosphopantetheine uptake in Drosophila, C. elegans, and HEK293 cells [161], whereas Zano et al. did not see any uptake of 4'-phosphopantetheine in mouse embryo fibroblasts or mouse hepatocytes [162]. In summary, the CoA biosynthetic pathway has the typical attributes of a prodrug activation system: broad substrate specificity, efficient, and allowing cell-type selectivity, making it a promising additional tool for medicinal chemists and researchers studying CoAutilizing enzymes.

\section{Acknowledgements}

Writing of this article and research in this area in the Auclair group were funded by the Canadian Institute of Health Research (CIHR), the Fonds de recherche du Quebec (FRQ) Audace program, the FRQ-RQRM initiative, the Australia National Health and Medical Research Council (NHMRC), the National Science and Engineering Research Council of Canada (NSERC), a McGill Fessenden Professorship, and a McGill Tomlinson Professorship. D.D. was supported by a scholarship from the Walter Sumner Foundation, and the Dr. and Mrs. Milton Leung fellowship in science. Finally, K.A. would also like to thank Prof. Ortiz de Montellano for his guidance, his support, and for providing a stimulating and instructive research environment during her postdoctoral research years.

\section{References}

[1] Ortiz de Montellano, P. R., Cytochrome P450-activated prodrugs. Future Med Chem 2013, 5 (2), 213-28. 
(C) This manuscript version is made available under the CC-BY-NC-ND 4.0 license https://creativecommons.org/licenses/by-nc-nd/4.0/

[2] Yanev, S. G.; Stoyanova, T. D.; Valcheva, V. V.; Ortiz de Montellano, P. R., Xanthates: Metabolism by flavoprotein-containing monooxygenases and antimycobacterial activity. Drug Metab Dispos 2018, 46 (8), 1091-5.

[3] Varfaj, F.; Zulkifli, S. N.; Park, H. G.; Challinor, V. L.; De Voss, J. J.; Ortiz de Montellano, P. R., Carboncarbon bond cleavage in activation of the prodrug nabumetone. Drug Metab Dispos 2014, 42 (5), 828-38.

[4] Rautio, J.; Kumpulainen, H.; Heimbach, T.; Oliyai, R.; Oh, D.; Jarvinen, T.; Savolainen, J., Prodrugs: design and clinical applications. Nat Rev Drug Discov 2008, 7 (3), 255-70.

[5] Abet, V.; Filace, F.; Recio, J.; Alvarez-Builla, J.; Burgos, C., Prodrug approach: An overview of recent cases. Eur J Med Chem 2017, 127, 810-827.

[6] Strauss, E., 7.11 - Coenzyme A biosynthesis and enzymology. In Comprehensive Natural Products II, Liu, H.-W.; Mander, L., Eds. Elsevier: Oxford, 2010; pp 351-410.

[7] Balibar, C. J.; Hollis-Symynkywicz, M. F.; Tao, J., Pantethine rescues phosphopantothenoylcysteine synthetase and phosphopantothenoylcysteine decarboxylase deficiency in Escherichia coli but not in Pseudomonas aeruginosa. J Bacteriol 2011, 193 (13), 3304-12.

[8] Kim, M. K.; An, Y. J.; Cha, S. S., The crystal structure of a novel phosphopantothenate synthetase from the hyperthermophilic archaea, Thermococcus onnurineus NA1. Biochem Biophys Res Commun 2013, $439(4), 533-8$.

[9] Yang, K.; Eyobo, Y.; Brand, L. A.; Martynowski, D.; Tomchick, D.; Strauss, E.; Zhang, H., Crystal structure of a type III pantothenate kinase: insight into the mechanism of an essential coenzyme $A$ biosynthetic enzyme universally distributed in bacteria. J Bacteriol 2006, 188 (15), 5532-40.

[10] Leonardi, R.; Chohnan, S.; Zhang, Y. M.; Virga, K. G.; Lee, R. E.; Rock, C. O.; Jackowski, S., A pantothenate kinase from Staphylococcus aureus refractory to feedback regulation by coenzyme A. J Biol Chem 2005, 280 (5), 3314-22.

[11] Awasthy, D.; Ambady, A.; Bhat, J.; Sheikh, G.; Ravishankar, S.; Subbulakshmi, V.; Mukherjee, K.; Sambandamurthy, V.; Sharma, U., Essentiality and functional analysis of type I and type III pantothenate kinases of Mycobacterium tuberculosis. Microbiology (Reading, England) 2010, 156 (Pt 9), 2691-701.

[12] Paige, C.; Reid, S. D.; Hanna, P. C.; Claiborne, A., The type III pantothenate kinase encoded by coaX is essential for growth of Bacillus anthracis. J Bacteriol 2008, 190 (18), 6271-5.

[13] Ogata, Y.; Katoh, H.; Asayama, M.; Chohnan, S., Role of prokaryotic type I and III pantothenate kinases in the coenzyme A biosynthetic pathway of Bacillus subtilis. Can J Microbiol 2014, 60 (5), 297-305.

[14] Dansie, L. E.; Reeves, S.; Miller, K.; Zano, S. P.; Frank, M.; Pate, C.; Wang, J.; Jackowski, S., Physiological roles of the pantothenate kinases. Biochem Soc Trans 2014, 42 (4), 1033-6.

[15] Rock, C. O.; Park, H.-W.; Jackowski, S., Role of feedback regulation of pantothenate kinase (CoaA) in control of coenzyme A levels in Escherichia coli. J Bacteriol 2003, 185 (11), 3410-5.

[16] Vallari, D. S.; Jackowski, S.; Rock, C. O., Regulation of pantothenate kinase by coenzyme A and its thioesters. J Biol Chem 1987, 262 (6), 2468-71.

[17] Yun, M.; Park, C. G.; Kim, J. Y.; Rock, C. O.; Jackowski, S.; Park, H. W., Structural basis for the feedback regulation of Escherichia coli pantothenate kinase by coenzyme A. J Biol Chem 2000, 275 (36), 28093-9.

[18] Ivey, R. A.; Zhang, Y. M.; Virga, K. G.; Hevener, K.; Lee, R. E.; Rock, C. O.; Jackowski, S.; Park, H. W., The structure of the pantothenate kinase.ADP.pantothenate ternary complex reveals the relationship between the binding sites for substrate, allosteric regulator, and antimetabolites. $J$ Biol Chem 2004, 279 (34), 35622-9.

[19] Song, W. J.; Jackowski, S., Kinetics and regulation of pantothenate kinase from Escherichia coli. J Biol Chem 1994, 269 (43), 27051-8. 
(C) This manuscript version is made available under the CC-BY-NC-ND 4.0 license https://creativecommons.org/licenses/by-nc-nd/4.0/

[20] Miller, J. R.; Ohren, J.; Sarver, R. W.; Mueller, W. T.; de Dreu, P.; Case, H.; Thanabal, V., Phosphopantetheine adenylyltransferase from Escherichia coli: investigation of the kinetic mechanism and role in regulation of coenzyme A biosynthesis. J Bacteriol 2007, 189 (22), 8196-205.

[21] Das, S.; Kumar, P.; Bhor, V.; Surolia, A.; Vijayan, M., Invariance and variability in bacterial PanK: a study based on the crystal structure of Mycobacterium tuberculosis PanK. Acta Crystallograph D 2006, 62 (Pt 6), 628-38.

[22] Bjorkelid, C.; Bergfors, T.; Raichurkar, A. K.; Mukherjee, K.; Malolanarasimhan, K.; Bandodkar, B.; Jones, T. A., Structural and biochemical characterization of compounds inhibiting Mycobacterium tuberculosis pantothenate kinase. J Biol Chem 2013, 288 (25), 18260-70.

[23] Paul, A.; Kumar, P.; Surolia, A.; Vijayan, M., Biochemical and structural studies of mutants indicate concerted movement of the dimer interface and ligand-binding region of Mycobacterium tuberculosis pantothenate kinase. Acta Crystallograph F 2017, 73 (Pt 11), 635-643.

[24] Chetnani, B.; Das, S.; Kumar, P.; Surolia, A.; Vijayan, M., Mycobacterium tuberculosis pantothenate kinase: possible changes in location of ligands during enzyme action. Acta Crystallograph D 2009, 65 (Pt 4), 312-25.

[25] Chetnani, B.; Kumar, P.; Abhinav, K. V.; Chhibber, M.; Surolia, A.; Vijayan, M., Location and conformation of pantothenate and its derivatives in Mycobacterium tuberculosis pantothenate kinase: insights into enzyme action. Acta Crystallograph D 2011, 67 (Pt 9), 774-83.

[26] Chetnani, B.; Kumar, P.; Surolia, A.; Vijayan, M., M. tuberculosis pantothenate kinase: dual substrate specificity and unusual changes in ligand locations. $J$ Mol Biol 2010, 400 (2), 171-85.

[27] Li, B.; Tempel, W.; Smil, D.; Bolshan, Y.; Schapira, M.; Park, H. W., Crystal structures of Klebsiella pneumoniae pantothenate kinase in complex with $N$-substituted pantothenamides. Proteins 2013, 81 (8), 1466-72.

[28] Hughes, S. J.; Antoshchenko, T.; Kim, K. P.; Smil, D.; Park, H. W., Structural characterization of a new $\mathrm{N}$-substituted pantothenamide bound to pantothenate kinases from Klebsiella pneumoniae and Staphylococcus aureus. Proteins 2014, 82 (7), 1542-8.

[29] Franklin, M. C.; Cheung, J.; Rudolph, M. J.; Burshteyn, F.; Cassidy, M.; Gary, E.; Hillerich, B.; Yao, Z. K.; Carlier, P. R.; Totrov, M.; Love, J. D., Structural genomics for drug design against the pathogen Coxiella burnetii. Proteins 2015, 83 (12), 2124-36.

[30] Brand, L. A.; Strauss, E., Characterization of a new pantothenate kinase isoform from Helicobacter pylori. J Biol Chem 2005, 280 (21), 20185-8.

[31] Hong, B. S.; Yun, M. K.; Zhang, Y. M.; Chohnan, S.; Rock, C. O.; White, S. W.; Jackowski, S.; Park, H. W.; Leonardi, R., Prokaryotic type II and type III pantothenate kinases: The same monomer fold creates dimers with distinct catalytic properties. Structure (London, England : 1993) 2006, 14 (8), 1251-61.

[32] Hughes, S. J.; Barnard, L.; Mottaghi, K.; Tempel, W.; Antoshchenko, T.; Hong, B. S.; Allali-Hassani, A.; Smil, D.; Vedadi, M.; Strauss, E.; Park, H. W., Discovery of potent pantothenamide inhibitors of Staphylococcus aureus pantothenate kinase through a minimal SARsStudy: Inhibition is due to trapping of the product. ACS Infect Dis 2016, 2 (9), 627-41.

[33] Rock, C. O.; Calder, R. B.; Karim, M. A.; Jackowski, S., Pantothenate kinase regulation of the intracellular concentration of coenzyme A. J Biol Chem 2000, 275 (2), 1377-83.

[34] delCardayre, S. B.; Stock, K. P.; Newton, G. L.; Fahey, R. C.; Davies, J. E., Coenzyme A disulfide reductase, the primary low molecular weight disulfide reductase from Staphylococcus aureus. Purification and characterization of the native enzyme. J Biol Chem 1998, 273 (10), 5744-51.

[35] Perera, V. R.; Newton, G. L.; Pogliano, K., Bacillithiol: a key protective thiol in Staphylococcus aureus. Expert Rev Anti Infect Ther 2015, 13 (9), 1089-1107. 
(C) This manuscript version is made available under the CC-BY-NC-ND 4.0 license https://creativecommons.org/licenses/by-nc-nd/4.0/

[36] Hong, B. S.; Senisterra, G.; Rabeh, W. M.; Vedadi, M.; Leonardi, R.; Zhang, Y. M.; Rock, C. O.; Jackowski, S.; Park, H. W., Crystal structures of human pantothenate kinases. Insights into allosteric regulation and mutations linked to a neurodegeneration disorder. J Biol Chem 2007, 282 (38), 27984-93.

[37] Leonardi, R.; Zhang, Y. M.; Yun, M. K.; Zhou, R.; Zeng, F. Y.; Lin, W.; Cui, J.; Chen, T.; Rock, C. O.; White, S. W.; Jackowski, S., Modulation of pantothenate kinase 3 activity by small molecules that interact with the substrate/allosteric regulatory domain. Chem Biol 2010, 17 (8), 892-902.

[38] Subramanian, C.; Yun, M. K.; Yao, J.; Sharma, L. K.; Lee, R. E.; White, S. W.; Jackowski, S.; Rock, C. O., Allosteric regulation of mammalian pantothenate kinase. J Biol Chem 2016, 291 (42), 22302-22314.

[39] Sharma, L. K.; Subramanian, C.; Yun, M. K.; Frank, M. W.; White, S. W.; Rock, C. O.; Lee, R. E.; Jackowski, S., A therapeutic approach to pantothenate kinase associated neurodegeneration. Nature Commun 2018, 9 (1), 4399.

[40] Yang, K.; Strauss, E.; Huerta, C.; Zhang, H., Structural basis for substrate binding and the catalytic mechanism of type III pantothenate kinase. Biochemistry 2008, 47 (5), 1369-80.

[41] Shimosaka, T.; Tomita, H.; Atomi, H., Regulation of Coenzyme A Biosynthesis in the hyperthermophilic bacterium Thermotoga maritima. J Bacteriol 2016, 198 (14), 1993-2000.

[42] Rowan, A. S.; Nicely, N. I.; Cochrane, N.; Wlassoff, W. A.; Claiborne, A.; Hamilton, C. J., Nucleoside triphosphate mimicry: a sugar triazolyl nucleoside as an ATP-competitive inhibitor of $B$. anthracis pantothenate kinase. Org Biomol Chem 2009, 7 (19), 4029-36.

[43] Daugherty, M.; Polanuyer, B.; Farrell, M.; Scholle, M.; Lykidis, A.; de Crecy-Lagard, V.; Osterman, A., Complete reconstitution of the human coenzyme A biosynthetic pathway via comparative genomics. $J$ Biol Chem 2002, 277 (24), 21431-9.

[44] Izard, T., A novel adenylate binding site confers phosphopantetheine adenylyltransferase interactions with coenzyme A. J Bacteriol 2003, 185 (14), 4074-80.

[45] Wubben, T.; Mesecar, A. D., Structure of Mycobacterium tuberculosis phosphopantetheine adenylyltransferase in complex with the feedback inhibitor CoA reveals only one active-site conformation. Acta Crystallograph F 2011, 67 (Pt 5), 541-5.

[46] Martin, D. P.; Drueckhammer, D. G., Separate enzymes catalyze the final two steps of coenzyme A biosynthesis in Brevibacterium ammoniagenes: Purification of pantetheine phosphate adenylyltransferase. Biochem Biophys Res Commun 1993, 192 (3), 1155-61.

[47] Izard, T.; Geerlof, A., The crystal structure of a novel bacterial adenylyltransferase reveals half of sites reactivity. $E M B O J$ 1999, 18 (8), 2021-30.

[48] O'Toole, N.; Barbosa, J. A.; Li, Y.; Hung, L. W.; Matte, A.; Cygler, M., Crystal structure of a trimeric form of dephosphocoenzyme A kinase from Escherichia coli. Protein Sci 2003, 12 (2), 327-36.

[49] Moreau, R. J.; Skepper, C. K.; Appleton, B. A.; Blechschmidt, A.; Balibar, C. J.; Benton, B. M.; Drumm, J. E., 3rd; Feng, B. Y.; Geng, M.; Li, C.; Lindvall, M. K.; Lingel, A.; Lu, Y.; Mamo, M.; Mergo, W.; Polyakov, V.; Smith, T. M.; Takeoka, K.; Uehara, K.; Wang, L.; Wei, J. R.; Weiss, A. H.; Xie, L.; Xu, W.; Zhang, Q.; de Vicente, J., Fragment-based drug discovery of inhibitors of phosphopantetheine adenylyltransferase from Gram-negative bacteria. J Med Chem 2018, 61 (8), 3309-24.

[50] Izard, T., The crystal structures of phosphopantetheine adenylyltransferase with bound substrates reveal the enzyme's catalytic mechanism. J Mol Biol 2002, 315 (4), 487-95.

[51] Skepper, C. K.; Moreau, R. J.; Appleton, B. A.; Benton, B. M.; Drumm, J. E., 3rd; Feng, B. Y.; Geng, M.; Hu, C.; Li, C.; Lingel, A.; Lu, Y.; Mamo, M.; Mergo, W.; Mostafavi, M.; Rath, C. M.; Steffek, M.; Takeoka, K. T.; Uehara, K.; Wang, L.; Wei, J. R.; Xie, L.; Xu, W.; Zhang, Q.; de Vicente, J., Discovery and optimization of phosphopantetheine adenylyltransferase inhibitors with Gram-negative antibacterial activity. J Med Chem 2018, 61 (8), 3325-49. 
(C) This manuscript version is made available under the CC-BY-NC-ND 4.0 license https://creativecommons.org/licenses/by-nc-nd/4.0/

[52] Morris, V. K.; Izard, T., Substrate-induced asymmetry and channel closure revealed by the apoenzyme structure of Mycobacterium tuberculosis phosphopantetheine adenylyltransferase. Protein Sci 2004, 13 (9), 2547-52.

[53] Kang, J. Y.; Lee, H. H.; Yoon, H. J.; Kim, H. S.; Suh, S. W., Overexpression, crystallization and preliminary $\mathrm{X}$-ray crystallographic analysis of phosphopantetheine adenylyltransferase from Enterococcus faecalis. Acta Crystallograph F 2006, 62 (Pt 11), 1131-3.

[54] Lee, H. H.; Yoon, H. J.; Kang, J. Y.; Park, J. H.; Kim, D. J.; Choi, K. H.; Lee, S. K.; Song, J.; Kim, H. J.; Suh, S. W., The structure of Staphylococcus aureus phosphopantetheine adenylyltransferase in complex with 3'-phosphoadenosine 5'-phosphosulfate reveals a new ligand-binding mode. Acta Crystallograph $F$ 2009, 65 (Pt 10), 987-91.

[55] Cheng, C. S.; Chen, C. H.; Luo, Y. C.; Chen, W. T.; Chang, S. Y.; Lyu, P. C.; Kao, M. C.; Yin, H. S., Crystal structure and biophysical characterisation of Helicobacter pylori phosphopantetheine adenylyltransferase. Biochem Biophys Res Commun 2011, 408 (2), 356-61.

[56] Edwards, T. E.; Leibly, D. J.; Bhandari, J.; Statnekov, J. B.; Phan, I.; Dieterich, S. H.; Abendroth, J.; Staker, B. L.; Van Voorhis, W. C.; Myler, P. J.; Stewart, L. J., Structures of phosphopantetheine adenylyltransferase from Burkholderia pseudomallei. Acta Crystallograph F 2011, 67 (Pt 9), 1032-7.

[57] Chatterjee, R.; Mondal, A.; Basu, A.; Datta, S., Transition of phosphopantetheine adenylyltransferase from catalytic to allosteric state is characterized by ternary complex formation in Pseudomonas aeruginosa. Biochim Biophys Acta 2016, 1864 (7), 773-86.

[58] Gupta, A.; Singh, P. K.; Iqbal, N.; Sharma, P.; Baraigya, H. R.; Kaur, P.; Umar, M. S.; Ahmad, F.; Sharma, A.; Owais, M.; Sharma, S.; Singh, T. P., Structural and binding studies of phosphopantetheine adenylyl transferase from Acinetobacter baumannii. Biochim Biophys Acta, Proteins Proteomics 2019, 1867 (6), 537-47.

[59] Seto, A.; Murayama, K.; Toyama, M.; Ebihara, A.; Nakagawa, N.; Kuramitsu, S.; Shirouzu, M.; Yokoyama, S., ATP-induced structural change of dephosphocoenzyme A kinase from Thermus thermophilus HB8. Proteins 2005, 58 (1), 235-42.

[60] Obmolova, G.; Teplyakov, A.; Bonander, N.; Eisenstein, E.; Howard, A. J.; Gilliland, G. L., Crystal structure of dephospho-coenzyme A kinase from Haemophilus influenzae. J Struct Biol 2001, 136 (2), 11925.

[61] Gong, X.; Chen, X.; Yu, D.; Zhang, N.; Zhu, Z.; Niu, L.; Mao, Y.; Ge, H., Crystal structure of Legionella pneumophila dephospho-CoA kinase reveals a non-canonical conformation of P-loop. J Struct Biol 2014, 188 (3), 233-9.

[62] Takahashi, H.; Inagaki, E.; Fujimoto, Y.; Kuroishi, C.; Nodake, Y.; Nakamura, Y.; Arisaka, F.; Yutani, K.; Kuramitsu, S.; Yokoyama, S.; Yamamoto, M.; Miyano, M.; Tahirov, T. H., Structure and implications for the thermal stability of phosphopantetheine adenylyltransferase from Thermus thermophilus. Acta Crystallograph D 2004, 60 (Pt 1), 97-104.

[63] Wubben, T. J.; Mesecar, A. D., Kinetic, thermodynamic, and structural insight into the mechanism of phosphopantetheine adenylyltransferase from Mycobacterium tuberculosis. J Mol Biol 2010, 404 (2), 202-19.

[64] de Jonge, B. L.; Walkup, G. K.; Lahiri, S. D.; Huynh, H.; Neckermann, G.; Utley, L.; Nash, T. J.; Brock, J.; San Martin, M.; Kutschke, A.; Johnstone, M.; Laganas, V.; Hajec, L.; Gu, R. F.; Ni, H.; Chen, B.; Hutchings, K.; Holt, E.; McKinney, D.; Gao, N.; Livchak, S.; Thresher, J., Discovery of inhibitors of 4'phosphopantetheine adenylyltransferase (PPAT) to validate PPAT as a target for antibacterial therapy. Antimicrob Agents Chemother 2013, 57 (12), 6005-15.

[65] Yoon, H. J.; Kang, J. Y.; Mikami, B.; Lee, H. H.; Suh, S. W., Crystal structure of phosphopantetheine adenylyltransferase from Enterococcus faecalis in the ligand-unbound state and in complex with ATP and pantetheine. Mol Cells 2011, 32 (5), 431-5. 
(C) This manuscript version is made available under the CC-BY-NC-ND 4.0 license https://creativecommons.org/licenses/by-nc-nd/4.0/

[66] Badger, J.; Sauder, J. M.; Adams, J. M.; Antonysamy, S.; Bain, K.; Bergseid, M. G.; Buchanan, S. G.; Buchanan, M. D.; Batiyenko, Y.; Christopher, J. A.; Emtage, S.; Eroshkina, A.; Feil, I.; Furlong, E. B.; Gajiwala, K. S.; Gao, X.; He, D.; Hendle, J.; Huber, A.; Hoda, K.; Kearins, P.; Kissinger, C.; Laubert, B.; Lewis, H. A.; Lin, J.; Loomis, K.; Lorimer, D.; Louie, G.; Maletic, M.; Marsh, C. D.; Miller, I.; Molinari, J.; Muller-Dieckmann, H. J.; Newman, J. M.; Noland, B. W.; Pagarigan, B.; Park, F.; Peat, T. S.; Post, K. W.; Radojicic, S.; Ramos, A.; Romero, R.; Rutter, M. E.; Sanderson, W. E.; Schwinn, K. D.; Tresser, J.; Winhoven, J.; Wright, T. A.; Wu, L.; $\mathrm{Xu}$, J.; Harris, T. J., Structural analysis of a set of proteins resulting from a bacterial genomics project. Proteins 2005, 60 (4), 787-96.

[67] Timofeev, V.; Smirnova, E.; Chupova, L.; Esipov, R.; Kuranova, I., X-ray study of the conformational changes in the molecule of phosphopantetheine adenylyltransferase from Mycobacterium tuberculosis during the catalyzed reaction. Acta Crystallograph D 2012, 68 (Pt 12), 1660-70.

[68] Mondal, A.; Chatterjee, R.; Datta, S., Umbrella sampling and X-ray crystallographic analysis unveil an Arg-Asp gate facilitating inhibitor binding inside phosphopantetheine adenylyltransferase allosteric cleft. J Phys Chem B 2018, 122 (5), 1551-9.

[69] Worthington, A. S.; Burkart, M. D., One-pot chemo-enzymatic synthesis of reporter-modified proteins. Org Biomol Chem 2006, 4 (1), 44-6.

[70] Leonardi, R.; Zhang, Y. M.; Rock, C. O.; Jackowski, S., Coenzyme A: back in action. Prog Lipid Res 2005, 44 (2-3), 125-53.

[71] Dai, M.; Feng, Y.; Tonge, P. J., Synthesis of crotonyl-oxyCoA: a mechanistic probe of the reaction catalyzed by enoyl-CoA hydratase. J Am Chem Soc 2001, 123 (3), 506-7.

[72] Nazi, I.; Koteva, K. P.; Wright, G. D., One-pot chemoenzymatic preparation of coenzyme A analogues. Anal biochem 2004, 324 (1), 100-5.

[73] Liu, Y.; Bruner, S. D., Rational manipulation of carrier-domain geometry in nonribosomal peptide synthetases. ChemBioChem 2007, 8 (6), 617-21.

[74] Tosin, M.; Spiteller, D.; Spencer, J. B., Malonyl carba(dethia)- and malonyl oxa(dethia)-coenzyme A as tools for trapping polyketide intermediates. ChemBioChem 2009, 10 (10), 1714-23.

[75] Strieker, M.; Nolan, E. M.; Walsh, C. T.; Marahiel, M. A., Stereospecific synthesis of threo- and erythro-beta-hydroxyglutamic acid during kutzneride biosynthesis. J Am Chem Soc 2009, 131 (37), 1352330.

[76] Zhang, W.; Shrestha, R.; Buckley, R. M.; Jewell, J.; Bossmann, S. H.; Stubbe, J.; Li, P., Mechanistic insight with $\mathrm{HBCH} 2 \mathrm{CoA}$ as a probe to polyhydroxybutyrate (PHB) synthases. ACS Chem Biol 2014, 9 (8), 1773-9.

[77] Weeks, A. M.; Wang, N.; Pelton, J. G.; Chang, M. C. Y., Entropy drives selective fluorine recognition in the fluoroacetyl-CoA thioesterase from Streptomyces cattleya. Proc Natl Acad Sci U S A 2018, 115 (10), E2193-e2201.

[78] Strauss, E.; de Villiers, M.; Rootman, I., Biocatalytic production of coenzyme A analogues. ChemCatChem 2010, 2 (8), 929-37.

[79] Meier, J. L.; Mercer, A. C.; Rivera, H., Jr.; Burkart, M. D., Synthesis and evaluation of bioorthogonal pantetheine analogues for in vivo protein modification. J Am Chem Soc 2006, 128 (37), 12174-84.

[80] Clarke, K. M.; Mercer, A. C.; La Clair, J. J.; Burkart, M. D., In vivo reporter labeling of proteins via metabolic delivery of coenzyme A analogues. J Am Chem Soc 2005, 127 (32), 11234-5.

[81] van der Westhuyzen, R.; Strauss, E., Michael acceptor-containing coenzyme A analogues as inhibitors of the atypical coenzyme A disulfide reductase from Staphylococcus aureus. J Am Chem Soc 2010, 132 (37), 12853-5.

[82] Lewis, R. A.; Nunns, L.; Thirlway, J.; Carroll, K.; Smith, C. P.; Micklefield, J., Active site modification of the beta-ketoacyl-ACP synthase FabF3 of Streptomyces coelicolor affects the fatty acid chain length of the CDA lipopeptides. Chem Commun (Cambridge, England) 2011, 47 (6), 1860-2. 
(C) This manuscript version is made available under the CC-BY-NC-ND 4.0 license https://creativecommons.org/licenses/by-nc-nd/4.0/

[83] Martin, D. P.; Drueckhammer, D. G., Combined chemical and enzymic synthesis of coenzyme A analogs. J Am Chem Soc 1992, 114 (18), 7287-8.

[84] Rootman, I.; de Villiers, M.; Brand, L. A.; Strauss, E., Creating cellulose-binding domain fusions of the coenzyme A biosynthetic enzymes to enable reactor-based biotransformations. ChemCatChem 2010, 2 (10), 1239-51.

[85] Strauss, E.; Begley, T. P., The selectivity for cysteine over serine in coenzyme A biosynthesis. ChemBioChem 2005, 6 (2), 284-6.

[86] Tran, L.; Broadhurst, R. W.; Tosin, M.; Cavalli, A.; Weissman, K. J., Insights into protein-protein and enzyme-substrate interactions in modular polyketide synthases. Chem Biol 2010, 17 (7), 705-16.

[87] Li, H. J.; Li, X.; Liu, N.; Zhang, H.; Truglio, J. J.; Mishra, S.; Kisker, C.; Garcia-Diaz, M.; Tonge, P. J., Mechanism of the intramolecular Claisen condensation reaction catalyzed by MenB, a crotonase superfamily member. Biochemistry 2011, 50 (44), 9532-44.

[88] Hamed, R. B.; Henry, L.; Gomez-Castellanos, J. R.; Asghar, A.; Brem, J.; Claridge, T. D.; Schofield, C. J., Stereoselective preparation of lipidated carboxymethyl-proline/pipecolic acid derivatives via coupling of engineered crotonases with an alkylmalonyl-CoA synthetase. Org Biomol Chem 2013, 11 (47), 8191-6.

[89] Zhang, W.; Chen, C.; Cao, R.; Maurmann, L.; Li, P., Inhibitors of polyhydroxyalkanoate (PHA) synthases: synthesis, molecular docking, and implications. ChemBioChem 2015, 16 (1), 156-66.

[90] Chen, C.; Cao, R.; Shrestha, R.; Ward, C.; Katz, B. B.; Fischer, C. J.; Tomich, J. M.; Li, P., Trapping of intermediates with substrate analog $\mathrm{HBOCOA}$ in the polymerizations catalyzed by class III polyhydroxybutyrate (PHB) synthase from Allochromatium vinosum. ACS Chem Biol 2015, 10 (5), 1330-9. [91] Agarwal, V.; Diethelm, S.; Ray, L.; Garg, N.; Awakawa, T.; Dorrestein, P. C.; Moore, B. S., Chemoenzymatic synthesis of acyl coenzyme A substrates enables in situ labeling of small molecules and proteins. Org Lett 2015, 17 (18), 4452-5.

[92] Ellis, B. D.; Milligan, J. C.; White, A. R.; Duong, V.; Altman, P. X.; Mohammed, L. Y.; Crump, M. P.; Crosby, J.; Luo, R.; Vanderwal, C. D.; Tsai, S. C., An oxetane-based polyketide surrogate to probe substrate binding in a polyketide synthase. J Am Chem Soc 2018, 140 (15), 4961-4.

[93] van Wyk, M.; Strauss, E., One-pot preparation of coenzyme A analogues via an improved chemoenzymatic synthesis of pre-CoA thioester synthons. Chem Commun (Cambridge, England) 2007, (4), 398400.

[94] Virga, K. G.; Zhang, Y. M.; Leonardi, R.; Ivey, R. A.; Hevener, K.; Park, H. W.; Jackowski, S.; Rock, C. O.; Lee, R. E., Structure-activity relationships and enzyme inhibition of pantothenamide-type pantothenate kinase inhibitors. BioorgMed Chem 2006, 14 (4), 1007-20.

[95] Mercer, A. C.; Meier, J. L.; Hur, G. H.; Smith, A. R.; Burkart, M. D., Antibiotic evaluation and in vivo analysis of alkynyl coenzyme A antimetabolites in Escherichia coli. Bioorg Med Chem Lett 2008, 18 (22), 5991-4.

[96] Stunkard, L. M.; Dixon, A. D.; Huth, T. J.; Lohman, J. R., Sulfonate/nitro bearing methylmalonylthioester isosteres applied to methylmalonyl-CoA decarboxylase structure-function studies. J Am Chem Soc 2019, 141 (13), 5121-4.

[97] Hammerer, F.; Chang, J. H.; Duncan, D.; Castaneda Ruiz, A.; Auclair, K., Small molecule restores itaconate sensitivity in Salmonella enterica: A potential new approach to treating bacterial infections. ChemBioChem 2016, 17 (16), 1513-7.

[98] Vong, K.; Tam, I. S.; Yan, X.; Auclair, K., Inhibitors of aminoglycoside resistance activated in cells. ACS Chem Biol 2012, 7 (3), 470-5.

[99] Guan, J.; Vong, K.; Wee, K.; Fakhoury, J.; Dullaghan, E.; Auclair, K., Cellular studies of an aminoglycoside potentiator reveal a new inhibitor of aminoglycoside resistance. ChemBioChem 2018, 19 (19), 2107-3. 
(C) This manuscript version is made available under the CC-BY-NC-ND 4.0 license https://creativecommons.org/licenses/by-nc-nd/4.0/

[100] Clifton, G.; Bryant, S. R.; Skinner, C. G., $N^{\prime}$-(substituted) pantothenamides, antimetabolites of pantothenic acid. Arch Biochem Biophys 1970, 137 (2), 523-8.

[101] Awuah, E.; Ma, E.; Hoegl, A.; Vong, K.; Habib, E.; Auclair, K., Exploring structural motifs necessary for substrate binding in the active site of Escherichia coli pantothenate kinase. Bioorg Med Chem 2014, 22 (12), 3083-90.

[102] de Villiers, M.; Barnard, L.; Koekemoer, L.; Snoep, J. L.; Strauss, E., Variation in pantothenate kinase type determines the pantothenamide mode of action and impacts on coenzyme A salvage biosynthesis. FEBS J 2014, 281 (20), 4731-53.

[103] Barnard, L.; Mostert, K. J.; van Otterlo, W. A. L.; Strauss, E., Developing pantetheinase-resistant pantothenamide antibacterials: Structural modification impacts on PanK interaction and mode of action. ACS Infect Dis 2018, 4 (5), 736-43.

[104] Jansen, P. A. M.; van der Krieken, D. A.; Botman, P. N. M.; Blaauw, R. H.; Cavina, L.; Raaijmakers, E. M.; de Heuvel, E.; Sandrock, J.; Pennings, L. J.; Hermkens, P. H. H.; Zeeuwen, P.; Rutjes, F.; Schalkwijk, J., Stable pantothenamide bioisosteres: novel antibiotics for Gram-positive bacteria. J Antibiot 2019, https://doi.org/10.1038/s41429-019-0196-6.

[105] Akinnusi, T. O.; Vong, K.; Auclair, K., Geminal dialkyl derivatives of $N$-substituted pantothenamides: synthesis and antibacterial activity. Bioorg Med Chem 2011, 19 (8), 2696-706.

[106] Guan, J.; Barnard, L.; Cresson, J.; Hoegl, A.; Chang, J. H.; Strauss, E.; Auclair, K., Probing the ligand preferences of the three types of bacterial pantothenate kinase. Bioorg Med Chem 2018, 26 (22), 5896902.

[107] Guan, J.; Hachey, M.; Puri, L.; Howieson, V.; Saliba, K. J.; Auclair, K., A cross-metathesis approach to novel pantothenamide derivatives. Beilstein J Org Chem 2016, 12, 963-8.

[108] Hoegl, A.; Darabi, H.; Tran, E.; Awuah, E.; Kerdo, E. S.; Habib, E.; Saliba, K. J.; Auclair, K., Stereochemical modification of geminal dialkyl substituents on pantothenamides alters antimicrobial activity. Bioorg Med Chem Lett 2014, 24 (15), 3274-7.

[109] Xun, J.; Huang, H.; Vogel, K. W.; Drueckhammer, D. G., The importance of the amide bond nearest the thiol group in enzymatic reactions of coenzyme A. Bioorg Chem 2005, 33 (2), 90-107.

[110] Sugie, Y.; Dekker, K. A.; Hirai, H.; Ichiba, T.; Ishiguro, M.; Shiomi, Y.; Sugiura, A.; Brennan, L.; Duignan, J.; Huang, L. H.; Sutcliffe, J.; Kojima, Y., CJ-15,801, a novel antibiotic from a fungus, Seimatosporium sp. J Antibiot 2001, 54 (12), 1060-5.

[111] Chiu, J. E.; Thekkiniath, J.; Choi, J. Y.; Perrin, B. A.; Lawres, L.; Plummer, M.; Virji, A. Z.; Abraham, A.; Toh, J. Y.; Zandt, M. V.; Aly, A. S. I.; Voelker, D. R.; Mamoun, C. B., The antimalarial activity of the pantothenamide alpha-PanAm is via inhibition of pantothenate phosphorylation. Sci Rep 2017, 7 (1), 14234.

[112] Choudhry, A. E.; Mandichak, T. L.; Broskey, J. P.; Egolf, R. W.; Kinsland, C.; Begley, T. P.; Seefeld, M. A.; Ku, T. W.; Brown, J. R.; Zalacain, M.; Ratnam, K., Inhibitors of pantothenate kinase: Novel antibiotics for Ssaphylococcal infections. Antimicrob Agents Chemother 2003, 47 (6), 2051-5.

[113] Howieson, V. M.; Tran, E.; Hoegl, A.; Fam, H. L.; Fu, J.; Sivonen, K.; Li, X. X.; Auclair, K.; Saliba, K. J., Triazole substitution of a labile amide bond stabilizes pantothenamides and improves their antiplasmodial potency. Antimicrob Agents Chemother 2016, 60 (12), 7146-52.

[114] Guan, J.; Tjhin, E. T.; Howieson, V. M.; Kittikool, T.; Spry, C.; Saliba, K. J.; Auclair, K., Structureactivity relationships of antiplasmodial pantothenamide analogues reveal a new way by which triazoles mimic amide bonds. ChemMedChem 2018, 13 (24), 2677-83.

[115] Spry, C.; Kirk, K.; Saliba, K. J., Coenzyme A biosynthesis: an antimicrobial drug target. FEMS Microbiol Rev 2008, 32 (1), 56-106.

[116] Moolman, W. J.; de Villiers, M.; Strauss, E., Recent advances in targeting coenzyme A biosynthesis and utilization for antimicrobial drug development. Biochem Soc Trans 2014, 42 (4), 1080-6. 
(C) This manuscript version is made available under the CC-BY-NC-ND 4.0 license https://creativecommons.org/licenses/by-nc-nd/4.0/

[117] Shapiro, J. A.; Varga, J. J.; Parsonage, D.; Walton, W.; Redinbo, M. R.; Ross, L. J.; White, E. L.; Bostwick, R.; Wuest, W. M.; Claiborne, A.; Goldberg, J. B., Identification of specific and nonspecific inhibitors of Bacillus anthracis Type III pantothenate kinase (PanK). ChemMedChem 2019, 14 (1), 78-82. [118] Zhang, Y. M.; Chohnan, S.; Virga, K. G.; Stevens, R. D.; Ilkayeva, O. R.; Wenner, B. R.; Bain, J. R.; Newgard, C. B.; Lee, R. E.; Rock, C. O.; Jackowski, S., Chemical knockout of pantothenate kinase reveals the metabolic and genetic program responsible for hepatic coenzyme A homeostasis. Chem Biol 2007, 14 (3), 291-302.

[119] Strauss, E.; Begley, T. P., The antibiotic activity of $N$-pentylpantothenamide results from its conversion to ethyldethia-coenzyme A, a coenzyme a antimetabolite. J Biol Chem 2002, 277 (50), 482059.

[120] Zhang, Y. M.; Frank, M. W.; Virga, K. G.; Lee, R. E.; Rock, C. O.; Jackowski, S., Acyl carrier protein is a cellular target for the antibacterial action of the pantothenamide class of pantothenate antimetabolites. J Biol Chem 2004, 279 (49), 50969-75.

[121] Thomas, J.; Cronan, J. E., Antibacterial activity of $N$-pentylpantothenamide is due to inhibition of coenzyme A synthesis. Antimicrob Agents Chemother 2010, 54 (3), 1374-7.

[122] Arnott, Z. L. P.; Nozaki, S.; Monteiro, D. C. F.; Morgan, H. E.; Pearson, A. R.; Niki, H.; Webb, M. E., The mechanism of regulation of pantothenate biosynthesis by the PanD-PanZ-AcCoA complex reveals an additional mode of action for the antimetabolite $N$-pentyl pantothenamide (N5-Pan). Biochemistry 2017, 56 (37), 4931-9.

[123] Monteiro, D. C. F.; Patel, V.; Bartlett, C. P.; Nozaki, S.; Grant, T. D.; Gowdy, J. A.; Thompson, G. S.; Kalverda, A. P.; Snell, E. H.; Niki, H.; Pearson, A. R.; Webb, M. E., The structure of the PanD/PanZ protein complex reveals negative feedback regulation of pantothenate biosynthesis by coenzyme A. Chem Biol 2015, 22 (4), 492-503.

[124] Brackett, S.; Waletzky, E.; Baker, M., The relation between pantothenic acid and Plasmodium gallinaceum infections in the chicken and the antimalarial activity of analogues of pantothenic acid. $J$ Parasitol 1946, 32 (5), 453-62.

[125] Bennett, T. P.; Trager, W., Pantothenic acid metabolism during avian malaria infection: pantothenate kinase activity in duck erythrocytes and in Plasmodium lophurae. J Protozool 1967, 14 (2), 214-6.

[126] Divo, A. A.; Geary, T. G.; Davis, N. L.; Jensen, J. B., Nutritional requirements of Plasmodium falciparum in culture. I. Exogenously supplied dialyzable components necessary for continuous growth. $J$ Protozool 1985, 32 (1), 59-64.

[127] Saliba, K. J.; Ferru, I.; Kirk, K., Provitamin B5 (pantothenol) inhibits growth of the intraerythrocytic malaria parasite. Antimicrob Agents Chemother 2005, 49 (2), 632-7.

[128] Spry, C.; van Schalkwyk, D. A.; Strauss, E.; Saliba, K. J., Pantothenate utilization by Plasmodium as a target for antimalarial chemotherapy. Infect Disord Drug Targets 2010, 10 (3), 200-16.

[129] Fletcher, S.; Avery, V. M., A novel approach for the discovery of chemically diverse anti-malarial compounds targeting the Plasmodium falciparum coenzyme A synthesis pathway. Malar J 2014, 13, 343.

[130] Spry, C.; Macuamule, C.; Lin, Z.; Virga, K. G.; Lee, R. E.; Strauss, E.; Saliba, K. J., Pantothenamides are potent, on-target inhibitors of Plasmodium falciparum growth when serum pantetheinase is inactivated. PLoS One 2013, 8 (2), e54974.

[131] Saliba, K. J.; Horner, H. A.; Kirk, K., Transport and metabolism of the essential vitamin pantothenic acid in human erythrocytes infected with the malaria parasite Plasmodium falciparum. J Biol Chem 1998, 273 (17), 10190-5.

[132] de Villiers, M.; Spry, C.; Macuamule, C. J.; Barnard, L.; Wells, G.; Saliba, K. J.; Strauss, E., Antiplasmodial mode of action of pantothenamides: Pantothenate kinase serves as a metabolic activator not as a target. ACS Infect Dis 2017, 3 (7), 527-41. 
(C) This manuscript version is made available under the CC-BY-NC-ND 4.0 license https://creativecommons.org/licenses/by-nc-nd/4.0/

[133] Macuamule, C. J.; Tjhin, E. T.; Jana, C. E.; Barnard, L.; Koekemoer, L.; de Villiers, M.; Saliba, K. J.; Strauss, E., A pantetheinase-resistant pantothenamide with potent, on-target, and selective antiplasmodial activity. Antimicrob Agents Chemother 2015, 59 (6), 3666-8.

[134] Tjhin, E. T.; Spry, C.; Sewell, A. L.; Hoegl, A.; Barnard, L.; Sexton, A. E.; Siddiqui, G.; Howieson, V. M.; Maier, A. G.; Creek, D. J.; Strauss, E.; Marquez, R.; Auclair, K.; Saliba, K. J., Mutations in the pantothenate kinase of Plasmodium falciparum confer diverse sensitivity profiles to antiplasmodial pantothenate analogues. PLoS Pathogens 2018, 14 (4), e1006918.

[135] van der Westhuyzen, R.; Hammons, J. C.; Meier, J. L.; Dahesh, S.; Moolman, W. J.; Pelly, S. C.; Nizet, V.; Burkart, M. D.; Strauss, E., The antibiotic CJ-15,801 is an antimetabolite that hijacks and then inhibits CoA biosynthesis. Chem Biol 2012, 19 (5), 559-71.

[136] Bacot-Davis, V. R.; Bassenden, A. V.; Berghuis, A. M., Drug-target networks in aminoglycoside resistance: hierarchy of priority in structural drug design. MedChemComm 2016, 7 (1), 103-13.

[137] Gao, F.; Yan, X.; Baettig, O. M.; Berghuis, A. M.; Auclair, K., Regio- and chemoselective 6'-Nderivatization of aminoglycosides: bisubstrate inhibitors as probes to study aminoglycoside $6^{\prime}-N$ acetyltransferases. Angew Chem Int Ed 2005, 44 (42), 6859-62.

[138] Magalhaes, M. L.; Vetting, M. W.; Gao, F.; Freiburger, L.; Auclair, K.; Blanchard, J. S., Kinetic and structural analysis of bisubstrate inhibition of the Salmonella enterica aminoglycoside 6'- $N$ acetyltransferase. Biochemistry 2008, 47 (2), 579-84.

[139] Gao, F.; Yan, X.; Shakya, T.; Baettig, O. M.; Ait-Mohand-Brunet, S.; Berghuis, A. M.; Wright, G. D.; Auclair, K., Synthesis and structure-activity relationships of truncated bisubstrate inhibitors of aminoglycoside 6'- $N$-acetyltransferases. J Med Chem 2006, 49 (17), 5273-81.

[140] Williams, J. O.; Roche, T. E.; McFadden, B. A., Mechanism of action of isocitrate lyase from Pseudomonas indigofera. Biochemistry 1971, 10 (8), 1384-90.

[141] McFadden, B. A.; Purohit, S., Itaconate, an isocitrate lyase-directed inhibitor in Pseudomonas indigofera. J Bacteriol 1977, 131 (1), 136-44.

[142] Patel, T. R.; McFadden, B. A., Caenorhabditis elegans and Ascaris suum: Inhibition of isocitrate lyase by itaconate. Exp Parasitol 1978, 44 (2), 262-8.

[143] Bambouskova, M.; Gorvel, L.; Lampropoulou, V.; Sergushichev, A.; Loginicheva, E.; Johnson, K.; Korenfeld, D.; Mathyer, M. E.; Kim, H.; Huang, L.-H.; Duncan, D.; Bregman, H.; Keskin, A.; Santeford, A.; Apte, R. S.; Sehgal, R.; Johnson, B.; Amarasinghe, G. K.; Soares, M. P.; Satoh, T.; Akira, S.; Hai, T.; de Guzman Strong, C.; Auclair, K.; Roddy, T. P.; Biller, S. A.; Jovanovic, M.; Klechevsky, E.; Stewart, K. M.; Randolph, G. J.; Artyomov, M. N., Electrophilic properties of itaconate and derivatives regulate the IKB inflammatory axis. Nature 2018, 556 (7702), 501-4.

[144] Mills, E. L.; Ryan, D. G.; Prag, H. A.; Dikovskaya, D.; Menon, D.; Zaslona, Z.; Jedrychowski, M. P.; Costa, A. S. H.; Higgins, M.; Hams, E.; Szpyt, J.; Runtsch, M. C.; King, M. S.; McGouran, J. F.; Fischer, R.; Kessler, B. M.; McGettrick, A. F.; Hughes, M. M.; Carroll, R. G.; Booty, L. M.; Knatko, E. V.; Meakin, P. J.; Ashford, M. L. J.; Modis, L. K.; Brunori, G.; Sevin, D. C.; Fallon, P. G.; Caldwell, S. T.; Kunji, E. R. S.; Chouchani, E. T.; Frezza, C.; Dinkova-Kostova, A. T.; Hartley, R. C.; Murphy, M. P.; O'Neill, L. A., Itaconate is an antiinflammatory metabolite that activates Nrf2 via alkylation of KEAP1. Nature 2018, 556 (7699), 113-7.

[145] O'Neill, L. A. J.; Artyomov, M. N., Itaconate: the poster child of metabolic reprogramming in macrophage function. Nat Rev Immunol 2019.

[146] Luan, H. H.; Medzhitov, R., Food fight: Role of itaconate and other metabolites in antimicrobial defense. Cell Metab 2016, 24 (3), 379-87.

[147] Dominguez-Andres, J.; Novakovic, B.; Li, Y.; Scicluna, B. P.; Gresnigt, M. S.; Arts, R. J. W.; Oosting, M.; Moorlag, S.; Groh, L. A.; Zwaag, J.; Koch, R. M.; Ter Horst, R.; Joosten, L. A. B.; Wijmenga, C.; Michelucci, A.; van der Poll, T.; Kox, M.; Pickkers, P.; Kumar, V.; Stunnenberg, H.; Netea, M. G., The itaconate pathway 
(C) This manuscript version is made available under the CC-BY-NC-ND 4.0 license https://creativecommons.org/licenses/by-nc-nd/4.0/

is a central regulatory node linking innate immune tolerance and trained immunity. Cell Metab 2019, 29 (1), 211-20.e5.

[148] Lampropoulou, V.; Sergushichev, A.; Bambouskova, M.; Nair, S.; Vincent, E. E.; Loginicheva, E.; Cervantes-Barragan, L.; Ma, X.; Huang, S. C.; Griss, T.; Weinheimer, C. J.; Khader, S.; Randolph, G. J.; Pearce, E. J.; Jones, R. G.; Diwan, A.; Diamond, M. S.; Artyomov, M. N., Itaconate links inhibition of succinate dehydrogenase with macrophage metabolic remodeling and regulation of inflammation. Cell Metab 2016, 24 (1), 158-66.

[149] Cordes, T.; Michelucci, A.; Hiller, K., Itaconic acid: The surprising role of an industrial compound as a mammalian antimicrobial metabolite. Annu Rev Nutr 2015, 35, 451-73.

[150] Williams, N. C.; O'Neill, L. A. J., A role for the Krebs cycle intermediate citrate in metabolic reprogramming in innate immunity and inflammation. Front Immunol 2018, 9, 141.

[151] Yu, X. H.; Zhang, D. W.; Zheng, X. L.; Tang, C. K., Itaconate: an emerging determinant of inflammation in activated macrophages. Immunol Cell Biol 2019, 97 (2), 134-41.

[152] Fang, F. C.; Libby, S. J.; Castor, M. E.; Fung, A. M., Isocitrate lyase (AceA) is required for Salmonella persistence but not for acute lethal infection in mice. Infect Immun 2005, 73 (4), 2547-9.

[153] Sasikaran, J.; Ziemski, M.; Zadora, P. K.; Fleig, A.; Berg, I. A., Bacterial itaconate degradation promotes pathogenicity. Nat Chem Biol 2014, 10 (5), 371-7.

[154] Santiviago, C. A.; Reynolds, M. M.; Porwollik, S.; Choi, S. H.; Long, F.; Andrews-Polymenis, H. L.; McClelland, M., Analysis of pools of targeted Salmonella deletion mutants identifies novel genes affecting fitness during competitive infection in mice. PLoS Pathogens 2009, 5 (7), e1000477.

[155] Periaswamy, B.; Maier, L.; Vishwakarma, V.; Slack, E.; Kremer, M.; Andrews-Polymenis, H. L.; McClelland, M.; Grant, A. J.; Suar, M.; Hardt, W. D., Live attenuated S. Typhimurium vaccine with improved safety in immuno-compromised mice. PLoS One 2012, 7 (9), e45433.

[156] Chen, M.; Huang, X.; Zhong, C.; Li, J.; Lu, X., Identification of an itaconic acid degrading pathway in itaconic acid producing Aspergillus terreus. Appl Microbiol Biotechnol 2016, 100 (17), 7541-8.

[157] Jansen, P. A. M.; van Diepen, J. A.; Ritzen, B.; Zeeuwen, P. L. J. M.; Cacciatore, I.; Cornacchia, C.; van Vlijmen-Willems, I. M. J. J.; de Heuvel, E.; Botman, P. N. M.; Blaauw, R. H.; Hermkens, P. H. H.; Rutjes, F. P. J. T.; Schalkwijk, J., Discovery of small molecule vanin inhibitors: New tools to study metabolism and disease. ACS Chem Biol 2013, 8 (3), 530-4.

[158] Jansen, P. A.; Hermkens, P. H.; Zeeuwen, P. L.; Botman, P. N.; Blaauw, R. H.; Burghout, P.; van Galen, P. M.; Mouton, J. W.; Rutjes, F. P.; Schalkwijk, J., Combination of pantothenamides with vanin inhibitors as a novel antibiotic strategy against Gram-positive bacteria. Antimicrob Agents Chemother 2013, 57 (10), 4794-800.

[159] de Villiers, M.; Macuamule, C.; Spry, C.; Hyun, Y. M.; Strauss, E.; Saliba, K. J., Structural modification of pantothenamides counteracts degradation by pantetheinase and improves antiplasmodial activity. ACS Med Chem Lett 2013, 4 (8), 784-9.

[160] Jackowski, S.; Rock, C. O., Metabolism of 4'-phosphopantetheine in Escherichia coli. J Bacteriol 1984, 158 (1), 115-20.

[161] Srinivasan, B.; Baratashvili, M.; van der Zwaag, M.; Kanon, B.; Colombelli, C.; Lambrechts, R. A.; Schaap, O.; Nollen, E. A.; Podgorsek, A.; Kosec, G.; Petkovic, H.; Hayflick, S.; Tiranti, V.; Reijngoud, D. J.; Grzeschik, N. A.; Sibon, O. C., Extracellular 4'-phosphopantetheine is a source for intracellular coenzyme A synthesis. Nat Chem Biol 2015, 11 (10), 784-92.

[162] Jackowski, S.; Rock, C. O., Metabolism of 4'-phosphopantetheine in Escherichia coli. J Bacteriol 1984, $158(1), 115-20$. 